\title{
- ÍMBOLOS EN EL ATUENDO DE LAS MUJERES MAYAS DE LA ANTIGÜEDAD. UNA APROXIMACIÓN ICONOGRÁFICA A TRES DISEÑOS SINGULARES ${ }^{1}$
}

\author{
ESTHER PARPAL CABANES \\ Universitat de València \\ esther.parpal@uv.es
}

Resumen: Este artículo forma parte de una investigación de mayor envergadura que tiene como objeto de estudio la representación femenina en el arte maya a través de los elementos que conforman sus retratos y definen sus identidades. Tanto las joyas, como la pintura corporal, los tocados o las prendas de vestir establecían un diálogo con el espectador de su tiempo que, si se analiza e interpreta en la actualidad, también puede aproximar al investigador al conocimiento sobre sus portadoras. Por ello, en esta ocasión presentamos concretamente el análisis de tres símbolos que forman parte de la indumentaria de algunas mujeres de la élite maya, entre los cuales cabe destacar el que luce la noble Señora de K'anpat en su traje, retratada en los murales pintados hallados por el equipo de investigación del Proyecto La Blanca, Petén, Guatemala, en el sitio arqueológico de Chilonché, ya que no se había visto antes en ninguna otra representación textil.

Palabras clave: Iconografía / maya / mujeres / símbolos / atuendo / identidad.

\section{SYMBOLS ON THE GARMENTS OF ANCIENT MAYA WOMEN. AN ICONOGRAPHIC APPROACH TO THREE UNIQUE DESIGNS}

\begin{abstract}
This paper is part of a larger research project that studies the representation of women in Maya art through the elements that make up their portraits and define their identities. The jewels, as well as the body paintings, the headdresses or the clothing, established a dialogue with the viewer of their time that if analyzed and interpreted today, can also bring the researcher closer to the knowledge about their wearers. For this reason, on this occasion we present a specific analysis of three symbols that form part of the clothing of some women of the Maya elite, among which the one worn by the noble Lady of K'anpat in her costume, portrayed in the painted murals found by the research team of the La Blanca Project, Petén, Guatemala, at the archaeological site of Chilonché, should be highlighted, as it had not been seen before in any other textile representation.
\end{abstract}

Key words: Iconography / Maya / women / symbols / garments / identity.

En ocasiones, cuando nos disponemos a emprender el análisis iconográfico de una obra, sentimos que la estamos diseccionando, como quien deshace un puzle para estudiar cada una de sus piezas por separado y, una vez comprendida la función de cada una, lo vuelve a montar para tratar de entender cómo actúa ese conjunto y qué lleva a esa imagen a ser de una manera y no de otra. Para ello,

\footnotetext{
* Fecha de recepción: 15 de abril de 2020 / Fecha de aceptación: 16 de noviembre de 2020.

1 La autora agradece expresamente el apoyo financiero del Vicerrectorado de Investigación de la Universidad de Valencia, a través del Programa de Ayudas para la formación de personal investigador de carácter predoctoral, dentro del marco del Programa "Atracción de Talento" con número de referencia UV-INV_PREDOC16F1-384467, que ha contribuido de forma determinante a hacer posible la presente investigación. Así como al Proyecto La Blanca, Petén, Guatemala, por la cesión de materiales, con especial mención a Cristina Vidal Lorenzo por la atenta revisión de este manuscrito y sus valiosas sugerencias. Hago extensivo este agradecimiento a los miembros del Proyecto Petén-Norte Naachtun, Philippe Nondédéo por su predisposición para facilitarme material fotográfico, y Julien Hiquet por sus acertados comentarios durante la realización de este trabajo. Por último, a Victòria Solanilla Demestre y a Yvonne Fleitman por alentar la publicación de este texto, y a las personas que lo han evaluado de manera anónima, por contribuir a la corrección y mejora del mismo.
} 
se atiende no solo a los aspectos formales y estilísticos de la obra, sino también, lógicamente, al contexto socio-cultural que la ve nacer y del que es partícipe activa.

De acuerdo con esto último, entendemos que en el proceso de creación de cada obra de arte interviene toda una suerte de factores que la hacen única, al mismo tiempo que la integran en su medio. De manera que, compartirá rasgos, estilos, influencias y significados con todas aquellas otras expresiones artísticas que forman parte del mismo entramado cultural o han podido beber de las mismas fuentes, aunque pertenezcan a diferentes períodos o tradiciones culturales.

Por ello, a los estudiosos siempre les ha resultado especialmente llamativo descubrir patrones de representación que se repiten en diferentes contextos que nada tienen que ver entre sí. A lo largo de la historia, este interrogante ha llevado a que numerosos investigadores se vieran tentados a involucrarse en la ardua tarea de encontrar un origen común a esas manifestaciones artísticas de los diferentes pueblos. Uno de los nombres más conocidos en este ámbito es el psicoanalista Carl Gustav Jung, cuya escuela de pensamiento todavía sigue ejerciendo una importante influencia en nuestros días. De acuerdo con este autor, existe un "inconsciente colectivo" que nos caracteriza como seres humanos y nos diferencia del resto de animales. Este determina nuestras conductas y se manifiesta en nuestras representaciones. De modo que, según sus teorías, existen unos arquetipos innatos en nuestro inconsciente que nos llevan a reproducir los mismos patrones y que explicaría por qué estos se repiten en diferentes momentos históricos y diversos contextos geográfi$\cos ^{2}{ }^{2}$ Esta teoría sobre los fenómenos culturales o formas simbólicas arquetípicas está también presente, entre otros, en la antropología filosófica de Ernst Cassirer. ${ }^{3}$ Él utiliza la expresión, "cultura espiritual" para referirse al lenguaje, al conocimiento científico, al mito, al arte y a la religión, porque entiende que las manifestaciones pueden ser diversas, pero responden a una unidad esencial, se originan en el espíritu. ${ }^{4}$ Así, según Cassirer la filosofía debe tratar de comprender su princi- pio formativo fundamental al afirmar que "Si la filosofía de la cultura logra aprehender y aclarar esos rasgos, entonces habrá cumplido en un sentido nuevo con su tarea de demostrar, frente a la pluralidad de manifestaciones del espíritu, la unidad de su esencia". 5

No obstante, aunque estas corrientes de pensamiento todavía tienen hoy en día fieles seguidores, otros tantos dan por superadas sus teorías y rechazan enérgicamente la posibilidad de que exista este tipo de símbolos naturales o interculturales. Los detractores de estas hipótesis argumentan que, aunque el ser humano sea anatómicamente igual, los sistemas de símbolos no son fruto de una creación fisiológica, sino cultural $y$, por tanto, dependen de unas normas sociales concretas, están condicionados por las diferencias que atañen a cada cultura $y$, además, dependen fuertemente de las estructuras relacionales de los individuos. ${ }^{6}$ En este sentido, expone Douglas que los símbolos no son innatos, pero sí lo que ella denomina "los sistemas naturales de simbolización", es decir, la forma de crearlos. Las asociaciones lógicas que los seres humanos hacen entre los objetos derivan necesariamente de su forma de relacionarse entre sí. Por lo tanto, cuando los sistemas sociales se asemejan, se puede arribar a un sistema de símbolos común o recurrente. ${ }^{7}$ Esto es muy claro, por ejemplo, en el panorama de las culturas mesoamericanas, las cuales comparten un parentesco cultural que les lleva a una creación coincidente. ${ }^{8}$ Retomaremos esta cuestión más adelante.

No es objeto de esta investigación profundizar más en este debate. Sin embargo, hacemos esta reflexión dado que puede resultar llamativo al lector reconocer los diseños que estudiaremos a continuación, en representaciones de otras culturas y de otros tiempos. Ya que, como formas geométricas, estas figuras no son exclusivas del área maya o incluso del área mesoamericana, sino que están presentes en la cultura visual a lo largo de la historia de la humanidad.

"Gracias a la Arqueología sabemos que el hombre alberga en sí una especie de sentido innato de la geometría. Así, en muchas regiones de la Tierra ha-

\footnotetext{
2 JUNG, Carl G., 1970.

${ }^{3}$ Sobre la noción de cultura de Ernst Cassirer véase: AMILBURU, María G., 1998.

${ }^{4}$ CASSIRER, Ernst, 1971, vol. 1, p. 12-60.

${ }^{5}$ CASSIRER, Ernst, 1971, vol. 1, p. 60.

${ }^{6}$ DOUGLAS, Mary, 1988, p. 8.

7 DOUGLAS, Mary, 1988, p. 8-9.

8 LÓPEZ AUSTIN, Alfredo, 2001, p. 55.
} 
llamos muestras de signos primarios, de data prehistórica y morfología idéntica". ${ }^{9}$ En estos casos, es decir, en el universo de los motivos geométricos, no es en el inconsciente o en los sistemas sociales afines donde debemos buscar la explicación, para entender la aparición frecuente de estos diseños en contextos culturales y temporales $\tan$ diferentes, sino en las formas. Pues, por supuesto, somos completamente conscientes de que, exceptuando el ámbito mesoamericano, la utilización de los diseños mayas, con el significado que estos comportan, nada tiene que ver con la presencia de estas mismas formas en el arte de otros pueblos del Viejo Mundo o de otras regiones americanas.

Veamos, por ejemplo, el caso de la serpiente, un atributo iconográfico frecuente en numerosas culturas y presente entre los símbolos que analizamos en este trabajo. De acuerdo con Frutiger, se trata del "organismo viviente que puede ser representado con la mayor simplicidad" y por lo tanto, aunque sin duda hay copiosas razones para justificar su presencia como elemento altamente simbólico en el arte de las diferentes civilizaciones, la mecánica de su diseño, la facilidad con la que se resuelve el trazo sinuoso de su cuerpo, han podido contribuir a su reiterada y similar representación. Lo mismo ocurre con otras formas de nuestro universo, como pueden ser los cuerpos celestes (luna, sol, estrella), las ondas del agua o las volutas de humo, por citar algunas. Especialmente cuando estas guardan un parecido con la realidad. $Y$, es igual para las formas geométricas. En este sentido, sí podemos hallar incluso teorías fisiológicas que se centren en la disposición de la musculatura de la mano y que expliquen el impulso de los movimientos así como el orden de los mismos (arriba-abajo, izquierda-derecha), como causante de los mencionados parecidos. ${ }^{10}$

Una vez aclarados estos aspectos, otra cuestión fundamental que nos planteamos a la hora de abordar el análisis de las figuras que aparecen en el atuendo de las mujeres mayas, es discernir qué las diferencia de los motivos y qué las convierte en símbolos. Y por qué hablamos de símbolos y no de signos.

Para ello, en primera instancia debemos entender la diferencia entre los diferentes niveles de significación. ${ }^{11}$ De acuerdo con García Mahíques ${ }^{12}$ consideramos que los motivos se encuentran en el nivel más básico o primario, puesto que responden a cuestiones de estilo, su función puede ser meramente ornamental $y$, para entenderlos y reconocerlos en el arte podemos valernos solamente de la experiencia cotidiana. En cambio, cuando estos diseños han sido escogidos porque albergan una significación para la cultura que los concibió, hablamos de símbolos. Es decir, que para entender el mensaje que contiene precisamos conocer la cosmovisión de ese pueblo, aproximarnos a la tradición cultural convencionalizada.

Algo más compleja es la distinción entre signo y símbolo, dos términos que, además, tienden a ser considerados, y empleados, como sinónimos. No así, en cambio, en el ámbito de la iconología. Esta disciplina distingue entre el signo que sintetiza una realidad, de acuerdo a unos códigos establecidos en un sistema social en concreto, mientras que el símbolo se utiliza para hacer tangible un aspecto, sentimiento o concepto abstracto, incomprensible para el ser humano, que tiene la necesidad de concretarlo de alguna manera. ${ }^{13}$ Chevalier lo explica con una metáfora, se refiere al símbolo como un transformador de corriente, que la canaliza y la hace utilizable. ${ }^{14}$

Los diferentes criterios a la hora de aplicar estos términos tan específicos son frecuentes en los textos de arte maya, especialmente en aquellos que analizan el atuendo, por lo que hemos considerado oportuno determinar cuáles son nuestras inclinaciones respecto a estas definiciones. ${ }^{15}$

\footnotetext{
9 FRUTIGER, Adrián 2007, p. 30.

10 FRUTIGER, Adrián 2007, p. 20, 187.

11 Para ello nos basamos en el método iconográfico-iconológico estructurado en el siglo XX por el historiador del arte Erwin Panofsky, véase: PANOFSKY, Erwin 1979, p. 13-26. Para consultar de manera más detallada el uso que hacemos de esta metodología en el estudio de las representaciones femeninas en el arte maya véase: PARPAL CABANES, Esther, 2017.

12 GARCÍA MAHÍQUES, Rafael, 2009, p. 34-37, 177-182, 249-250.

13 GARCÍA MAHÍQUES, Rafael, 2009, p. 345-347.

14 CHEVALIER, Jean, 1986, p. 29

15 Véase, por ejemplo, el trabajo de LOOPER, Mathew G., 2000, donde se utiliza el término "motivos" para referirse a "símbolos" como los que ahora analizamos, presentes en los huipiles de las mujeres mayas de la Antigüedad. O, el texto de MACLEOD, Morna, 2004, en el que los términos "signo" y "símbolo" son empleados como sinónimos cuando estudia las figuras representadas en los trajes femeninos mayas.
} 
Así, en el tema que nos ocupa, podríamos entender como signo el prefijo IX utilizado para determinar que un título es femenino. ${ }^{16}$ El nombre escrito de una reina maya es visible a los ojos del hombre, pero no la feminidad, la fertilidad o el poder que ese título entraña. Eso ha de evocarse por medio de símbolos, como los que ahora pasamos a exponer.

Si bien es cierto que existieron diseños que se repitieron constantemente para adornar los atuendos femeninos mayas, como la flor, la red o la $T$, que nos llevan a pensar y a hablar de modas y estilos cuya elección podría no ir más allá de una tendencia o gusto estético, cuando profundizamos un poco más en una cultura cuyo arte era sustancialmente conceptual, comprobamos que, generalmente, se trata de figuras cargadas de contenido que apelan a la capacidad interpretativa del espectador.

Así, la representación de una flor bordada sobre una prenda textil mediante unas formas que imiten la realidad, podría constituir un motivo, ya que nos basta con la propia experiencia cotidiana para reconocerla. En cambio, sería necesario llevar a cabo un análisis iconográfico para conocer si en el seno de la cultura maya, los elementos florales se asocian con algún significado, por ejemplo, con la fertilidad. No obstante, el nivel comunicativo todavía puede ser mayor. Por ejemplo, si a esto le sumamos que esa flor forma parte de los atributos iconográficos de una reina que está siendo presentada ante su pueblo como una mujer fértil, que ha dado a luz al siguiente gobernante. Además, que era crucial enaltecer la imagen de esta dama con una potente simbología porque su presencia en la imagen contribuye a legitimar el ascenso al poder de su hijo. Y, si a esto se le suma, que en la coyuntura de ese período de gobierno en concreto, eso era fundamental ya que los conflictos interdinásticos estaban poniendo en duda el derecho al trono de este gobernante en concreto, estaríamos ascendiendo al ámbito de la iconología. Esto es así porque se está realizando una interpretación iconográfica de la representación, para la cual no basta solo con los conocimientos generales sobre esa sociedad, sino conocer la coyuntura específica, el contexto social de la creación de esa imagen.
Llegar a este nivel de conocimientos sobre una obra de arte no siempre es fácil, especialmente en una cultura como es la maya, tan alejada en tiempo y espacio y, para la que no siempre contamos con todas las fuentes arqueológicas, iconográficas o epigráficas que necesitamos. Ya sea por la falta de ellas o la dificultad de acceso a las mismas, o por el mal estado de conservación en que la obra ha llegado hasta nuestros días. Aun así, es mucho lo que el análisis iconográfico puede ofrecernos como paso previo para aproximarnos un poco más al conocimiento de esta cultura, en los casos en los que los vestigios artísticos lo permiten.

\section{El textil maya como campo de significación}

No en vano expresa Irma Otzoy que "El traje maya también provee al mundo un texto para ser leído". ${ }^{17} \mathrm{Y}$ es que son numerosas las investigaciones que se han aventurado en el estudio de los textiles y ornamentos en el arte mesoamericano ${ }^{18}$ demostrando que detrás de las "modas" de las antiguas civilizaciones precolombinas existía una compleja red de significantes y significados. Esta concurrencia de símbolos exhibidos en la indumentaria provoca que estudios recientes como el de Cara G. Tremain recurran a la semiótica como herramienta en el estudio de los trajes de la corte maya. ${ }^{19}$

$Y$ es que, de entre los atributos iconográficos que pueden aproximarnos mejor al conocimiento sobre las mujeres mayas de antaño, el traje es uno de los más importantes. No sólo por ser uno de los elementos visuales más elocuentes debido al espacio que ocupa en la escena, sino porque es la característica principal que ha servido históricamente para diferenciar a mujeres de hombres en el arte de esta antigua civilización. Entre las señoras de la nobleza, raramente encontramos retratos en los que muestren el torso descubierto o las rodillas.

Así, aunque la mayoría de las investigaciones que nos preceden se han centrado en estudiar los tipos de vestimenta y los contextos en los que eran utilizados unos trajes u otros, cada vez son más los especialistas que, conscientes del contenido simbólico que albergan los diseños que decoran estas prendas, se dedican a profundizar en el estudio de

${ }^{16}$ Para consultar la representación del signo -ix "señora, mujer", véase: KETTUNEN, Harri; HELMKE, Christophe, 2011, p. 82/162.

17 OTZOY, Irma, 1992, p. 104.

18 Véase ASTURIAS DE BARRIOS, Linda, 1985; BRUHNS, Karen O., 1988; JOYCE, Rosemary, 1992, 1998; HENDRICKSON, Carol, 1995; MACLEOD, Morna, 2004; HOLSBEKE, Mireille; MONTOYA, Julia, 2008; MILLER, Mary, 2009; GARCÍA BARRIOS, Ana; VÁZQUEZ LÓPEZ, Verónica, 2011; VIDAL LORENZO, Cristina; PARPAL CABANES, Esther, 2016, entre otras.

19 TREMAIN, Cara G. 2017, p. 80-84. 
sus significados. ${ }^{20}$ Entre estos trabajos cabe destacar el que llevó a cabo Mathew G. Looper, en el que reconstruyó las imágenes de algunos de los huipiles ${ }^{21}$ más significativos que lucen las mujeres del Clásico en las representaciones artísticas mayas, con la colaboración de Thomas Tolles. ${ }^{22}$ A través de esta investigación, visibilizó todo un conjunto de motivos simbólicos plasmados en los textiles, que debido a la erosión y a los problemas de conservación de algunos monumentos, en ocasiones, son difíciles de estudiar a partir de las fotografías y de los dibujos preexistentes. Además, en este mismo volumen recogió las interpretaciones que se había hecho hasta entonces sobre el significado de algunos de estos símbolos, y añadió sus propias conclusiones a partir de sus análisis.

Además de los diseños plasmados sobre los huipiles que fueron estudiados por Looper y otros autores, uno de los patrones bordados, sobresaliente entre las antiguas mujeres de la nobleza maya, que también ha dado lugar a copiosos estudios por su trascendencia simbólica, es el conocido "símbolo de red". Su presencia en las prendas de vestir refiere a la fertilidad de quien lo porta al simbolizar la superficie fértil de la tierra de la que brota la planta del maíz que procura alimento y por tanto, vida. ${ }^{23}$ Por ello, el denominado "traje de red" está fuertemente vinculado a las mujeres mayas, especialmente a aquellas relacionadas con el poder. De hecho, las principales portadoras de este tipo de vestido en la tradición iconográfica de esta civilización son las madres de quienes gobernaron en los grandes reinos. Algunos de los ejemplos más significativos los protagonizan las mujeres de la dinastía Kanu'l de Calakmul o las de Palenque. Su presencia se da especialmente en escenas de entronización, en las cuales el símbolo de red contribuye a la identificación de estas damas como las encargadas principales de transmitir el linaje real y atestiguar el derecho del gobernante, su hijo, al trono. ${ }^{24}$

Pero el símbolo que conforma el traje de red es solo uno entre la enorme cantidad de símbolos que, como decíamos, fueron bordados sobre las prendas de vestir mayas. Sin embargo, tal y como afirman acertadamente Vidal Lorenzo, Vázquez de Ágredos y Horcajada Campos en su trabajo sobre "La indumentaria de los personajes femeninos de la élite maya y el papel de la mujer en su elaboración", desafortunadamente son escasos los vestigios textiles conservados de época prehispánica dada su fragilidad ante los medios extremos en los que se desarrollaron. ${ }^{25}$ Por ello, en el presente estudio nos valemos principalmente de las fuentes iconográficas, epigráficas y etnográficas para aproximarnos al significado de tres de estos símbolos en concreto, que todavía no han sido estudiados de manera exhaustiva cuando aparecen formando parte de los bordados en las prendas de vestir femeninas.

Cabe señalar que este artículo forma parte de mi investigación doctoral, cuyo objetivo es el estudio de los retratos de las mujeres del período Clásico en el arte oficial. A nivel metodológico, nuestra labor parte de una primera fase heurística, que precede al análisis iconográfico y a la interpretación metodológica de las imágenes. Esto nos lleva a estudiar cada uno de los elementos que conforman dichos retratos, pues son los que contribuyen a construir una imagen concreta sobre las mujeres mayas de esta época. En este sentido, aproximarnos al significado de los atributos iconográficos plasmados en su indumentaria constituye una de las partes ineludibles de todo el proceso.

Nuestro trabajo se desarrolla bajo la premisa de que las prendas de vestir a través del color, la forma y el diseño, entre otros aspectos, establecían un diálogo con el espectador de su tiempo que, si se analiza e interpreta en la actualidad, también puede aproximar al investigador al conocimiento sobre sus portadoras.

\section{El símbolo de las tres circunferencias}

En primer lugar, abordamos el estudio de un símbolo que adorna frecuentemente los textiles que lucen los personajes representados en las vasijas de estilo códice, provenientes del departamento de Petén en Guatemala. A pesar de su sencillez, consideramos que su constante presencia plasmada

\footnotetext{
20 LOOPER, Mathew G., 2000; MORRIS, Walter 1984, 2006; DUPIECH CAVALERI, Danielle, 1999, 2017; KOPALKOVA, Alla, 2018, entre otros.

${ }^{21}$ Se trata de prendas de ropa semejantes a las túnicas. Están formadas por varias piezas de tela que se cosen entre sí. Generalmente, no tienen mangas y cubren el cuerpo desde los hombros hasta los tobillos. Existen numerosas variedades, en función del diseño de los cuellos, el uso de unos tejidos u otros, así como una amplia gama de colores y bordados.

22 LOOPER, Mathew G., 2000.

23 LE FORT, Geneviève, 2002, p. 120.

24 GARCÍA BARRIOS, Ana; VÁZQUEZ LÓPEZ, Verónica, 2011, p. 82.

25 VIDAL LORENZO, Cristina; VÁZQUEZ DE ÁGREDOS, Mª Luisa; HORCAJADA CAMPOS, Patricia, 2011, p. 82.
} 


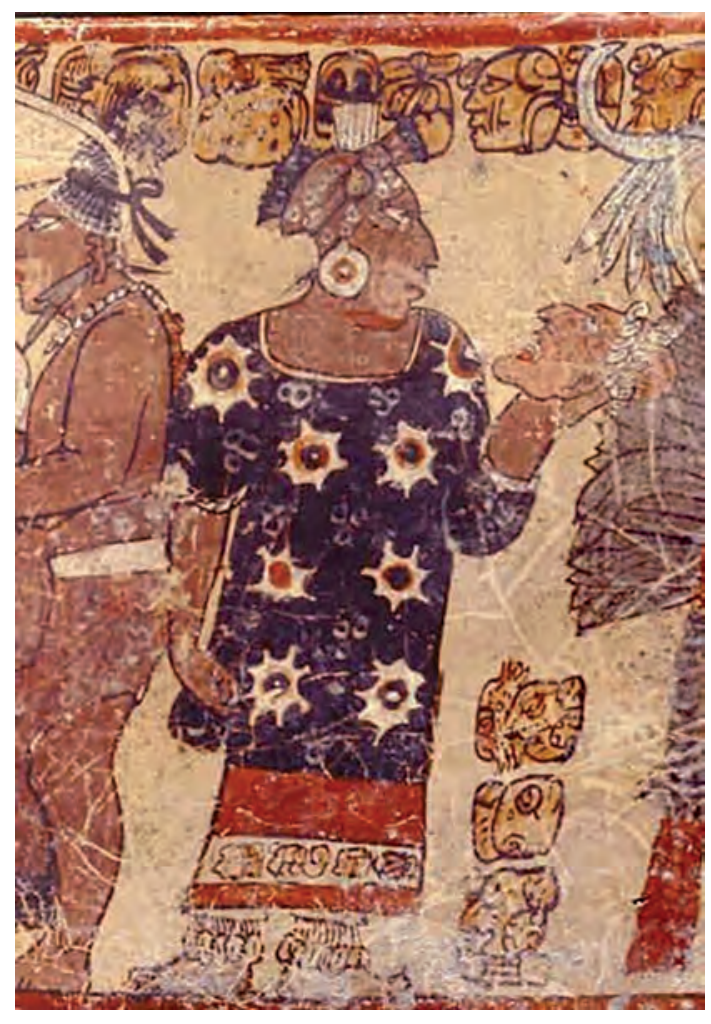

b

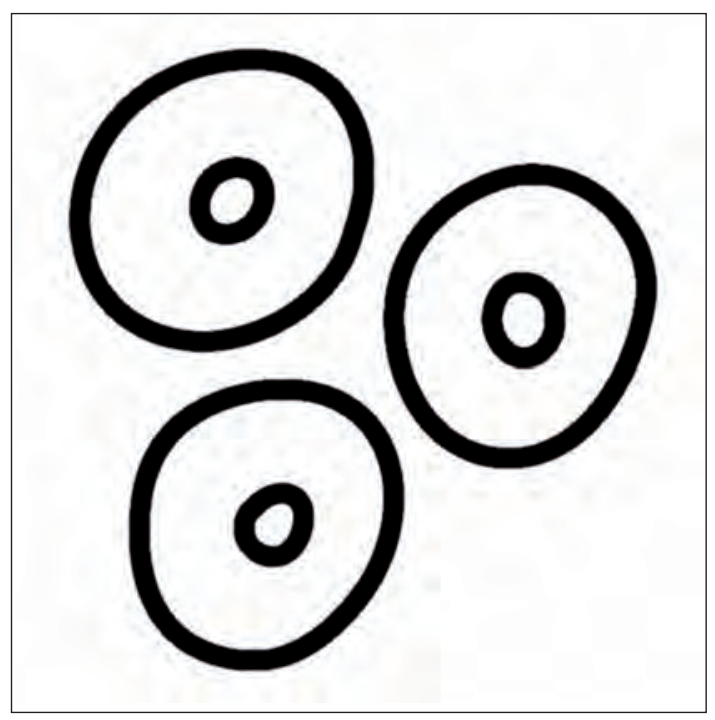

a

sobre los tejidos podría estar dotando a la prenda de un gran contenido simbólico.

Se trata de un diseño compuesto por tres pequeñas circunferencias dispuestas unas al lado de las otras conformando un racimo que, como es habitual, se repite varias veces en la misma prenda

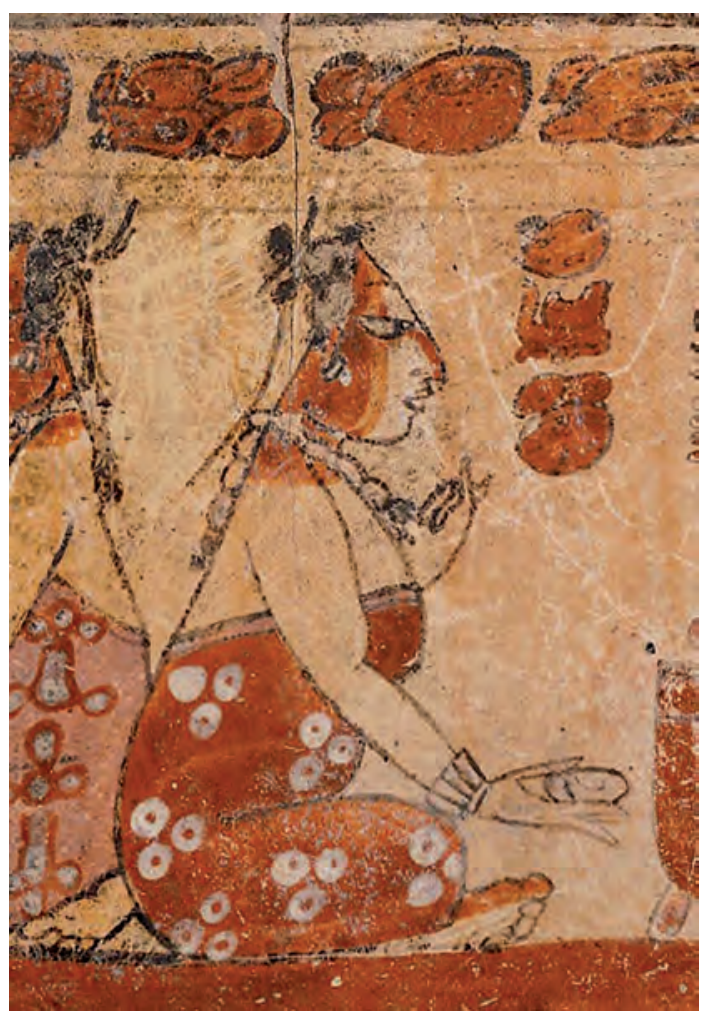

c

Fig. 1. a) El símbolo de las tres circunferencias. Dibujo de la autora. b) Detalle de la Vasija K0764 (c) Justin Kerr. c) Detalle de la Vasija 1987.719, Museum of Fine Arts, Boston.

textil. Generalmente, dichos círculos presentan un diminuto punto en el centro (Fig. 1a).

En 1947, Morley ya se refiere brevemente en su obra a algunos diseños textiles frecuentes en la antigüedad maya, entre los cuales figuran este tipo de elementos circulares. ${ }^{26}$

${ }^{26}$ MORLEY, Sylvanus G., 1946, p. 406. 

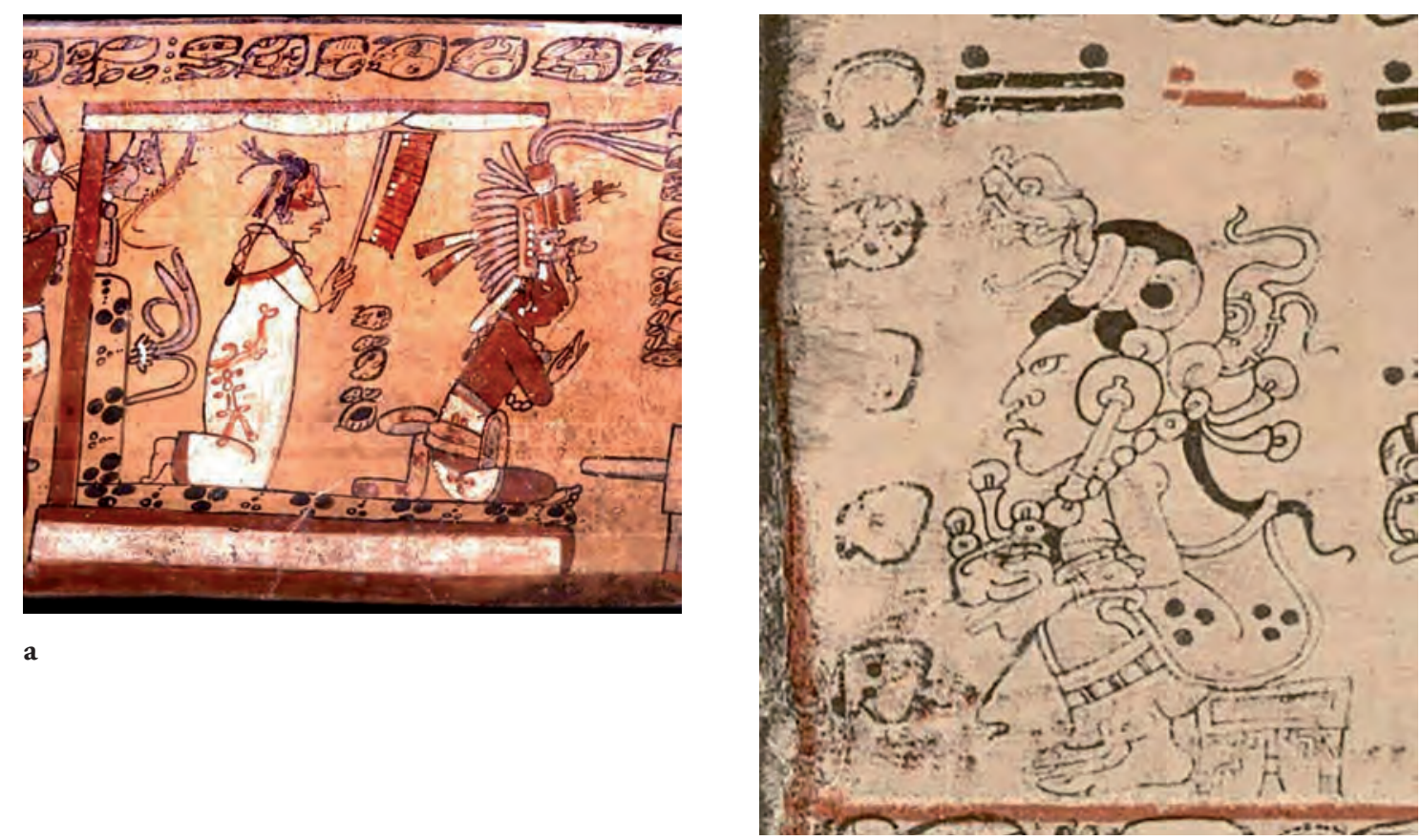

b

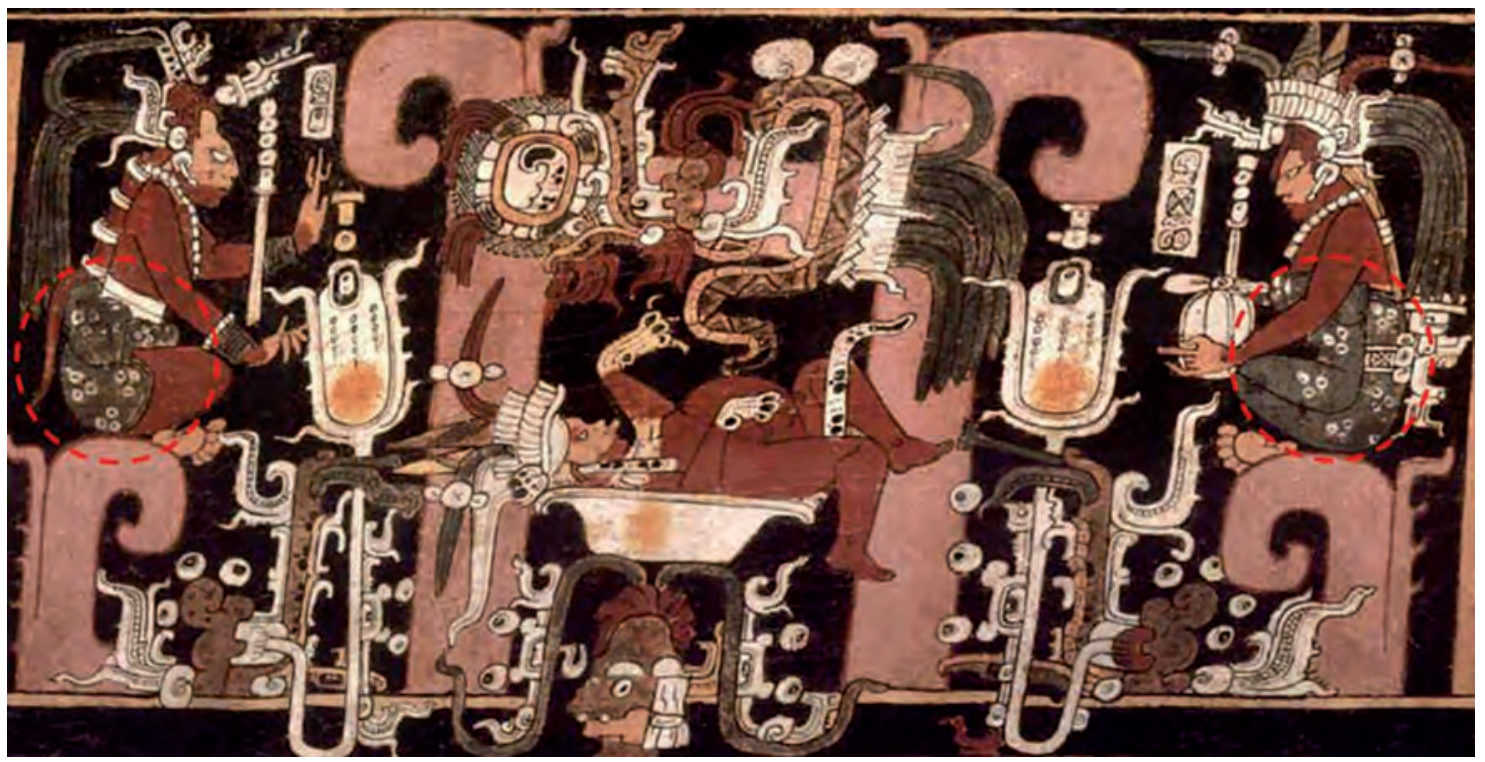

c

Fig. 2. a) Detalle de la Vasija K5456 @ Justin Kerr. b) Detalle del 1er registro, página 18, Códice de Dresde. FAMSI. "El Códice Dresde" (en línea). c) Detalle de la Vasija K1184 @ Justin Kerr modificado por la autora. Los círculos en rojo señalan las prendas de vestir donde puede verse el símbolo de las tres circunferencias.

A simple vista, su disposición nos lleva necesariamente a pensar en las pequeñas motas negras que representan las manchas de la piel del jaguar y que observamos habitualmente en las tapicerías de los cojines y los tronos que figuran en las esce- nas protagonizadas por la élite que exhiben las vasijas de cerámica policromadas (Fig. 2a). Asimismo, su presencia está documentada en otros soportes plásticos como por ejemplo, los códices mayas. En los que aparecen justamente sobre la in- 
dumentaria de una de las divinidades femeninas representadas (Fig. 2b).

En el ámbito de la epigrafía también observamos estas tres mismas circunferencias dispuestas de manera similar en los glifos que hacen referencia al jaguar. ${ }^{27}$

La presencia de este símbolo en el estampado de los ropajes que visten tanto la figura masculina como la femenina, presentes en una escena sobre el mito del bebé jaguar, podría sugerir de manera todavía más clara una vinculación entre este diseño y dicho animal sagrado (Fig. 2c). La escena a la que nos referimos está pintada sobre un vaso ritual que se encuentra expuesto en el Museo de Bellas Artes de Boston, catalogado en la base de datos de Justin $\mathrm{Kerr}^{28}$ como K1184. En el centro protagoniza la escena el bebé jaguar acostado sobre un disco que a su vez descansa sobre un cráneo de lirio acuático y de cuyo vientre surge, a modo de cordón umbilical, una serpiente. A ambos lados le acompañan dos figuras identificadas como sus padres que, en este caso, son quienes lucen los vestidos con el símbolo de las tres circunferencias. Esta representación plasma la delgada línea que separa la vida de la muerte, ese momento justo de transformación. ${ }^{29}$

Por lo tanto, una primera hipótesis sobre el significado de este símbolo podría versar sobre la relación de este con la piel del jaguar, elemento a su vez vinculado fuertemente a la nobleza y al poder en general, entre los mayas de antaño.

Sin embargo, observamos que, cuando los artistas representan textiles confeccionados con piel de jaguar, este tipo de tejido se distingue claramente en la pintura, pues además era un elemento que se utilizaba para expresar ostentación y poder de quien lo poseía (Fig. 2a). En cambio, el patrón que nosotros estudiamos se manifiesta de manera mucho más discreta, incluso mezclado con otros atributos iconográficos (Fig. 1b).

Además, no solo lo hallamos en escenas de carácter palaciego. En el citado Museo de Boston se con- serva también una vasija de cerámica policromada que representa una escena de carácter doméstico protagonizada por varias mujeres, en la que podemos observar este atributo iconográfico en la prenda que viste la mujer sentada frente a las demás figuras, delante de un recipiente para alimentos (Fig. 1C).

Esta escena nos lleva a pensar en otra posible significación. En los hogares mayas era frecuente, y todavía hoy en día lo es en muchas comunidades indígenas, encontrar en el fogón de cocinar tres piedras dispuestas de manera similar a cómo lo observamos en el diseño textil que nos ocupa. De hecho, según los sondeos realizados por Quiroz y Cantú entre 2005 y 2010 en los territorios de Yucatán y Quintana Roo "Los resultados evidencian una amplia distribución y uso del fogón abierto de tres piedras (...)". ${ }^{30}$ Son muchos los especialistas que relacionan dichas piedras de uso cotidiano, con aquellas que según la mitología maya simbolizan el establecimiento del centro del cosmos, conmemoran "la colocación de las tres piedras-trono por parte de los dioses". ${ }^{31}$ Estas tres piedras determinan el centro del hogar, la cocina y, en la cosmología maya, el centro del Cosmos. La Estela C de Quiriguá es uno de los ejemplos artísticos mayas que narran este suceso, quién las coloca y dónde se asientan. ${ }^{32}$ Asimismo, la conocida vasija de los Siete Dioses pintada por Ah-Maxam, ${ }^{33}$ artista real de Naranjo, nos muestra la colocación de la primera de ellas. ${ }^{34}$

En este sentido, si recurrimos nuevamente a la epigrafía observamos que el glifo de la roca o piedra TUUN presenta justamente unos círculos dispuestos en forma de racimo en su diseño. Y, más concretamente, Stone y Zender nos muestran que el signo de pedernal TOOK', exhibe tres círculos. ${ }^{35}$

A modo de conclusión, siendo las mujeres sujetos activos en la creación del universo maya, tal y como prueban sus creencias, ${ }^{36}$ así como las encargadas en el mundo terrenal de las labores domésticas de preparación de alimentos y otras labores rela-

\footnotetext{
27 Para consultar la representación del signo BALAM "jaguar" o HIX "referencia a un felino", véase: KETTUNEN, Harri; HELMKE, Christophe, 2011, p. 77/162, 81/162.

${ }^{28}$ Para consultar la base de datos de Justin Kerr, véase: http://www.mayavase.com/.

${ }^{29}$ MARTIN, Simon, 2002, p. 72

30 QUIROZ CARRANZA, Joaquín; CANTÚ GUTIERREZ, Citlalli, 2012, p. 273.

31 VIDAL LORENZO, Cristina; RIVERA DORADO, Miguel, 2017, p. 12.

32 FREIDEL, David; SCHELE, Linda; PARKER, Joy, 1993, p. 65.

33 Véase en: http://research.mayavase.com/kerrmaya_hires.php?vase=2796.

34 REENTS-BUDET, Dorie, 1994, 64 y FREIDEL, David; SCHELE, Linda; PARKER, Joy, 1993, p. 67.

35 STONE, Andrea; ZENDER, Marc, 2011, p. 83.

36 VIDAL LORENZO, Cristina; RIVERA DORADO, Miguel, 2017, p. 29-31, 207-208.
} 


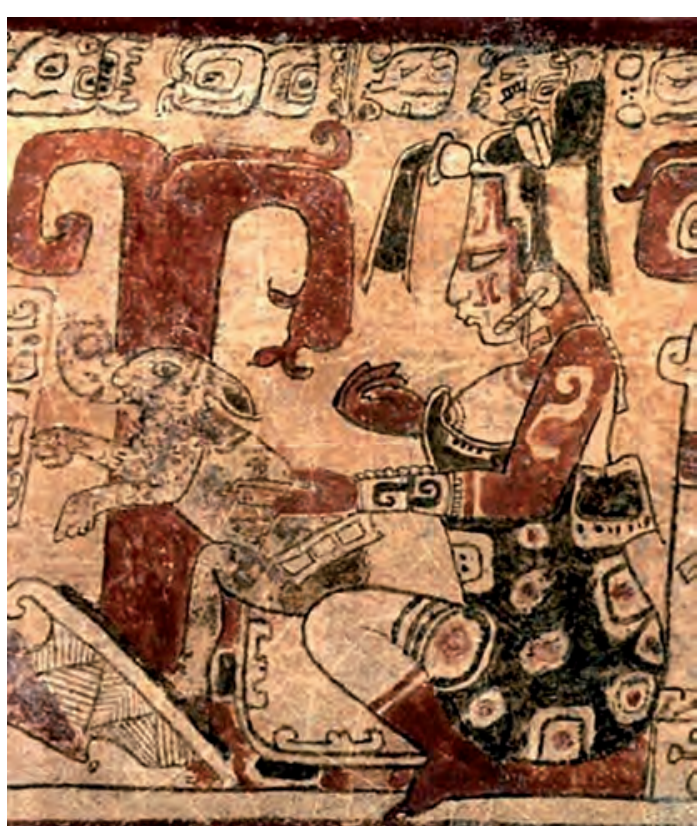

b

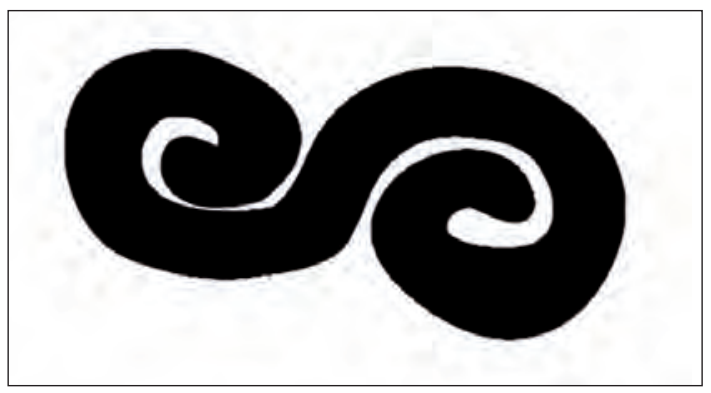

a

cionadas con la creación, ${ }^{37}$ no sería arriesgado relacionar este símbolo con sendas funciones femeninas. Ambas vinculadas entre sí a través de las citadas piedras para el horno y las piedras trono mencionadas en los mitos. Lo cual explicaría su reiterada presencia en los atuendos de algunas de estas antiguas damas.

No obstante, cabe señalar que la creación no fue considerada una tarea exclusiva del género femenino, sino que se trataba de una actividad complementaria llevada a cabo por una pareja masculina-femenina. ${ }^{38}$ Por lo que no es de extrañar que algunos hombres luzcan también el símbolo de las tres circunferencias en sus trajes (Fig. 2c). Y, que observemos este tipo de círculos en otros glifos sobresalientes como es el glifo AJAW. ${ }^{39}$

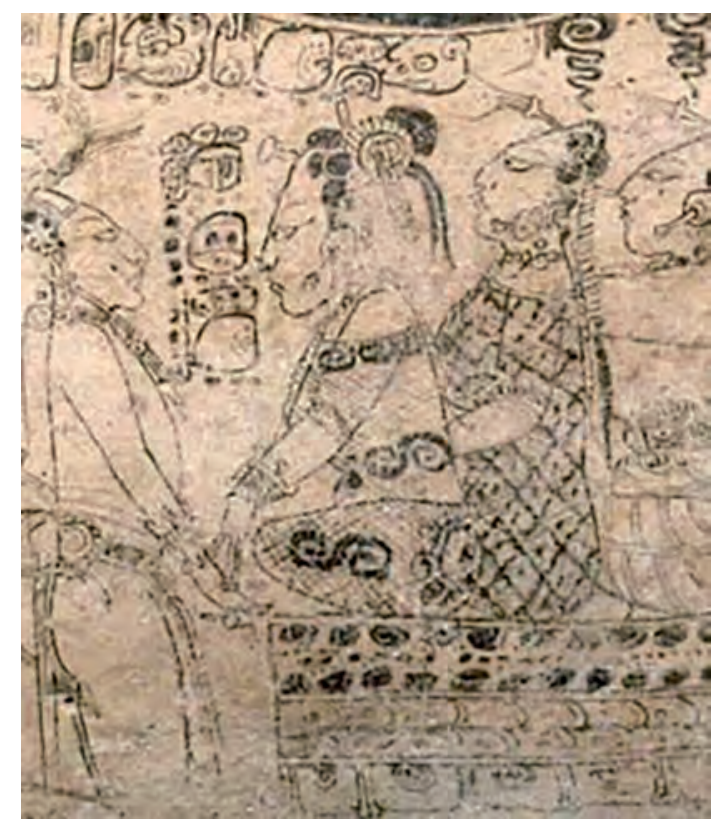

c

Fig. 3. a) El símbolo de la $\mathrm{S}$ horizontal. Dibujo de la autora. b) Detalle de la Vasija 0559 (C) Justin Kerr. c) Detalle de la Vasija 2772 (c) Justin Kerr.

\section{El símbolo de la S horizontal}

A continuación, analizamos otro de los diseños presente en los atuendos de las mujeres mayas dotado de una gran carga simbólica.

En el imaginario maya está vinculado a la Diosa Luna entre otros, y tiene la forma de una $S$ dispuesta de forma horizontal. Se trata de un atributo iconográfico muy repetido que cuenta con una amplia variedad de formas y ubicaciones en el arte maya, además de aparecer reflejado en las vestimentas (Figura 3a).

En una de las vasijas de cerámica policromada que hace referencia a las diferentes fases de la luna conservada, una vez más, en el Museo de Bellas Artes de Boston, lo localizamos entre los ornamentos de

37 VIDAL LORENZO, Cristina; PARPAL CABANES, Esther, 2017, p. 45-46.

38 Para consultar la base de datos de Justin Kerr, véase: http://www.mayavase.com/.

39 Para consultar la representación del signo AJAW, "gobernante”, véase: THOMPSON, J. Eric S., 1962, p. 251. 
la Diosa Ix Chel. Esta se encuentra de cuclillas, en posición de parto, alumbrando a un conejo y el símbolo aparece pintado en su brazo y en su brazalete (Fig. 3b). Asimismo, se aprecia con claridad en el vestido de esta misma divinidad representada sobre un trono, en otra pieza cerámica catalogada como K2772 en la base de datos de Justin Kerr (Fig. 3c).

Además de en la cerámica, su presencia vinculada a la deidad femenina también ha sido documentada en los códices mayas por otras autoras como Danielle Dupiech, quien realiza una elogiable labor de recopilación de atributos iconográficos bordados en los textiles actuales de la península de Yucatán e investiga su origen en tiempos prehispánicos. Entre estos, identifica el motivo "S" y enumera los registros en los que aparece en el Códice de Madrid así como su localización..$^{40}$ Generalmente, se encuentra formando parte del atuendo de la Diosa Chac Chel, conformando el cuerpo de la serpiente de su tocado. No obstante, la página donde el símbolo aparece representado con mayor claridad es en el registro 68a del Códice de Dresde, en el que aparece dos veces conformando una nube sobre la cabeza de sendas representaciones del Dios Chaahk (Fig. 4a). ${ }^{41}$ Asimismo, Dupiech reconoce el atributo en los textiles yucatecos contemporáneos (Fig. 4b) y halla una relación entre esta representación actual, la que aparece documentada en dos de los códices mayas conservados y el que aparece en uno de los escasos fragmentos textiles hallados en contexto arqueológico, concretamente en el cenote de Chichen Itzá (Fig. 4c). En las conclusiones de su estudio y teniendo en cuenta las investigaciones previas en torno a este atributo iconográfico (pues también aparece en la arquitectura y en la epigrafía, por ejemplo) expone que se trata de símbolos relacionados con la lluvia $y$, en consecuencia, con la fertilidad. ${ }^{42}$

Otras respuestas sobre el uso y el significado del citado símbolo "S" nos las concede la epigrafía. El logograma MUYAL que hace referencia a la nube es representado precisamente siguiendo la forma de una "S" horizontal. ${ }^{43}$ Además de estar presente en códices y textiles, algunos autores lo localizan formando parte de la decoración de los palacios de los nobles o conformando el cuerpo de una serpiente, por ejemplo, en la Estela 4 de Ucanal. ${ }^{44}$
Además, es interesante observar que este símbolo no es exclusivo de la población maya, puesto que ha sido localizado dentro del sistema de símbolos olmeca. F. Kent Reilly dedica un artículo a analizar la posible conexión entre este símbolo presente en el arte de ambas civilizaciones precolombinas. Su presencia en los monumentos olmecas de Chalcatzingo revela también una relación de este símbolo con el agua. Asimismo, este autor deduce de la representación de la "S" horizontal junto al felino, un vínculo también entre este símbolo y el autosacrificio de sangre (Fig. 4e). Lo cual coincidiría nuevamente con la forma del cuerpo de la serpiente y las volutas del humo que en la iconografía maya forman parte de las visiones durante los autosacrificios de sangre. A su vez, representa un estadio del cielo, por lo que se trata de un símbolo relacionado con lo sobrenatural tanto entre los antiguos olmecas como entre los antiguos mayas. ${ }^{45}$

Por otra parte, como símbolo relacionado con la Iluvia, el MUYAL se encuentra necesariamente vinculado al Dios Chaahk. García Barrios recoge numerosos ejemplos de apelativos de la mencionada deidad que incluyen alusiones a la nube, así como representaciones en las que el MUYAL forma parte de la representación iconográfica del dios (Fig. 4a). ${ }^{46}$

Finalmente, además de en las elocuentes vasijas de estilo códice, entre los vestigios arqueológicos lo hallamos también pintado en algunos restos de recipientes cerámicos que en su día sirvieron para contener líquidos, precisamente y, de manera significativa, en los fragmentos correspondientes a la parte de la vertedera (Fig. 4d).

En resumen, el símbolo de la "S" horizontal identificado por los investigadores como el logograma MUYAL que se refiere a la nube $y$, como tal, reconocido como uno de los estadios del cielo según las creencias mayas, aparece representado como un símbolo vinculado a la lluvia y al agua y esta, a la fertilidad de la tierra. Ambos, además de estar relacionados con el Dios Chaahk, son atributos asociados a la Diosa Luna en sus diferentes versiones (joven o anciana), como ejemplo divino en el mundo sobrenatural para las mujeres de la tierra. De modo que ello podría explicar su presencia continua en la indumentaria femenina.

\footnotetext{
40 DUPIECH CAVALERI, Danielle, 2017, p. 258-264.

41 DUPIECH CAVALERI, Danielle, 2017, p. 259-260 y GARCíA BARRIOS, Ana, 2008, p. 159.

42 DUPIECH CAVALERI, Danielle, 2017, p. 263.

${ }^{43}$ Para consultar la representación del logograma MUYAL, "nube", véase STONE, Andrea; ZENDER, Marc, 2011, p. 143.

44 STONE, Andrea; ZENDER, Marc, 2011, p. 142-143.

45 REILLY, F. Kent III, 1996, p. 413-424.

46 GARCÍA BARRIOS, Ana, 2008.
} 

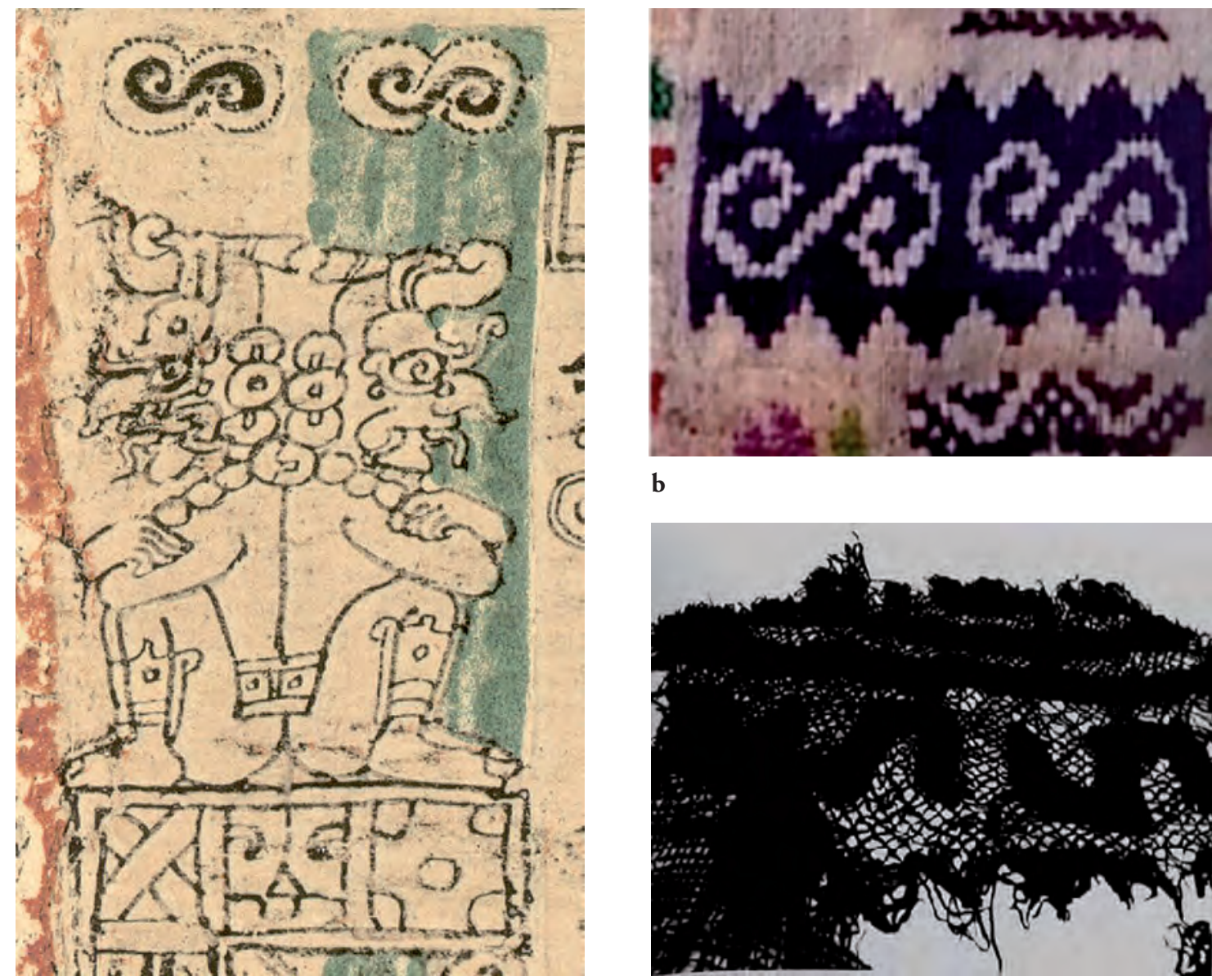

b
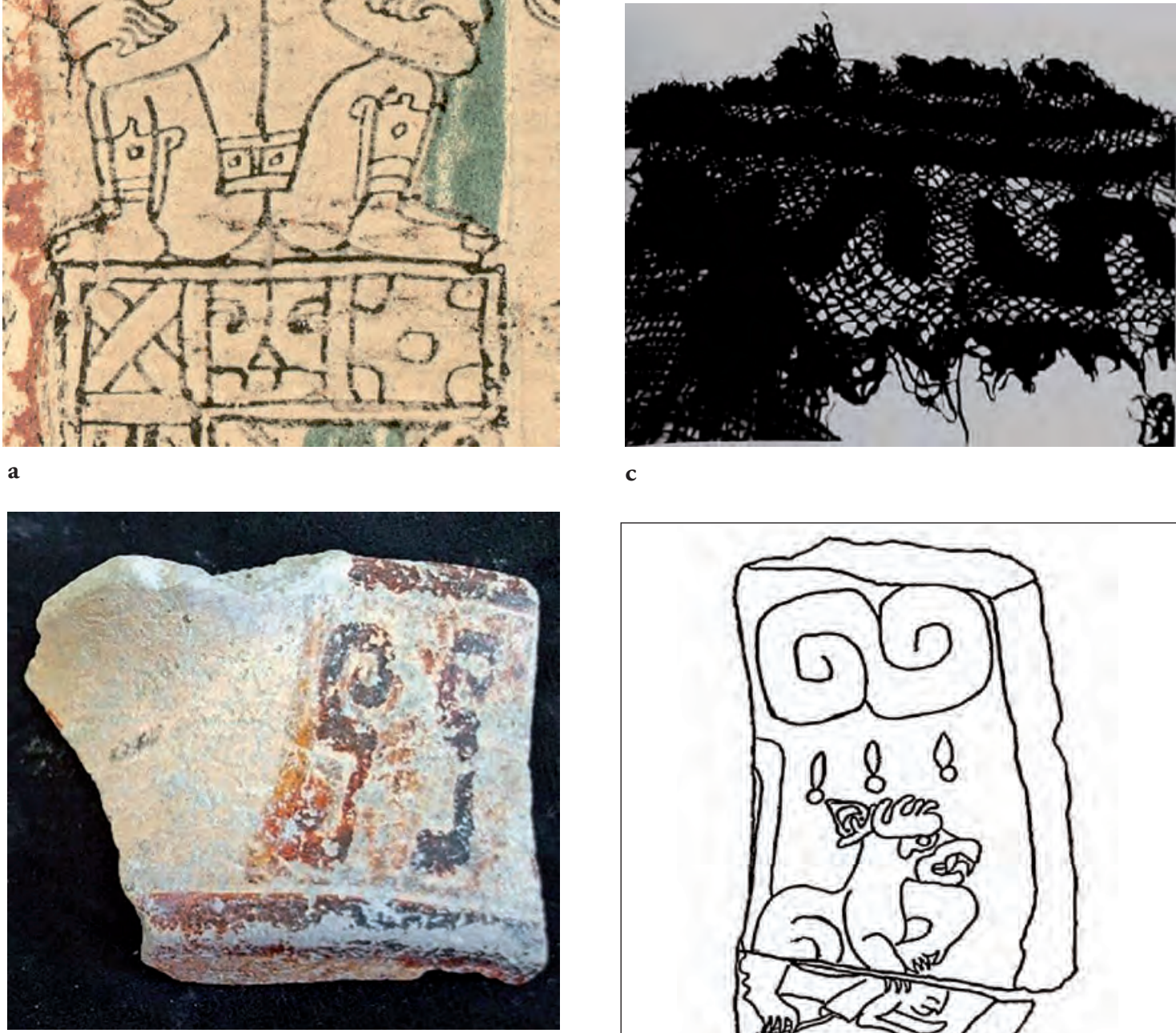

d

c

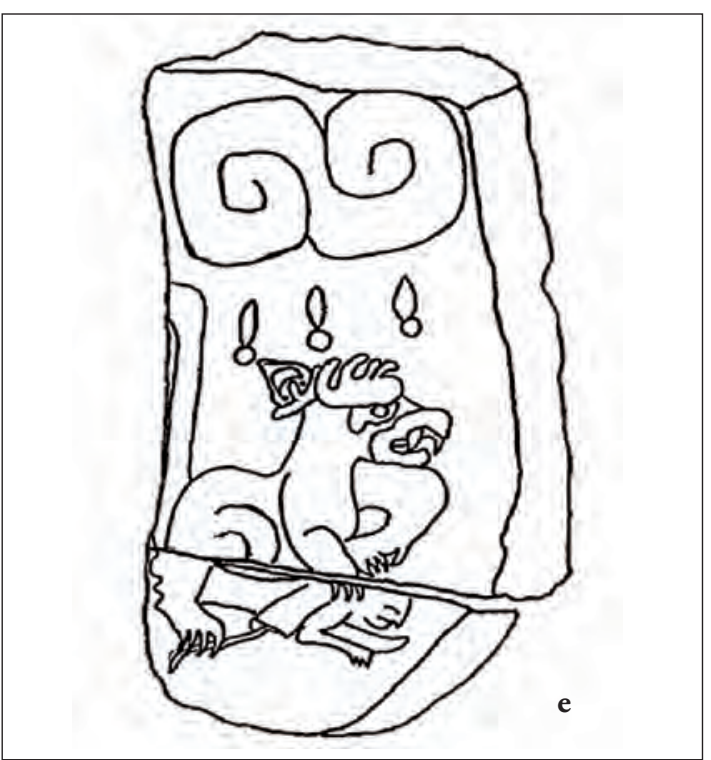

Fig. 4. a) Detalle de la página 68a, Códice de Dresde. FAMSI. "El Códice Dresde" (en línea). b) Motivo no 423. Donatila Be Balam, Maní, Yucatán, México. Tomado de Dupiech Cavaleri, Danielle, 2017, p. 258. c) Diseño de "S" sobre un fragmento de textil proveniente del cenote de Chichen Itzá, Museo Regional de Antropología, Palacio Cantón, Mérida (INAH), P. LVII, no 504. Tomado de DUPIECH CAVALERI, Danielle, 2017, p. 259. d) Fragmento de vertedera. Clásico Temprano. Fotografía de Julien Hiquet / () Proyecto Naachtún. e) Monumento 31, Chalcatzingo. Dibujo de F. Kent Reilly. Tomado de REILLY, F. Kent, 1996. 


\section{El símbolo de grecas en espiral}

Finalmente, a la luz de los hallazgos realizados por parte del equipo de investigación del Proyecto "La Blanca y su entorno" en la antigua ciudad maya de Chilonché, ${ }^{47}$ analizamos un símbolo que, al contrario que los anteriores, no se repite tan asiduamente en las representaciones de textiles del arte maya hasta ahora conocidas.

Nuestro último objeto de estudio es el símbolo que aparece pintado sobre el traje de la figura femenina protagonista de una de las escenas pintadas en el Cuarto 6 del Edificio 3E1 de la Acrópolis de Chilonché (Figs. $5 a$ y $5 b$ ).

Esta señora fue identificada como Ix K'anpat Ajaw, es decir, que se trataba de una princesa procedente de una ciudad conocida como K'anpat, tal vez el nombre maya para la ciudad de Chilonché o alguna de los alrededores. Y la noble señora parece estar sobresaltada ante la batalla que se está librando entre los individuos de la pared oeste, algunos de los cuales están identificados también con el glifo de la misma ciudad. ${ }^{48}$ Su pertenencia al linaje regio se ve reforzada por el uso de una exquisita prenda de ropa, decorada con un símbolo que, hasta día de hoy, no se ha reconocido, plasmado de este modo, en ninguna otra prenda textil.

En un trabajo publicado en 2016, las investigadoras Lina Barrios, Miriam Nimatuj, Raquel García y Yamanik Pablo identifican entre la indumentaria femenina maya representada en el Códice maya de Dresde hasta once prendas textiles diferentes, con sus correspondientes variantes, y hallan en casi todas ellas paralelismos con la moda femenina maya contemporánea de todo el territorio. ${ }^{49}$ Este estudio nos ofrece un rico abanico de la variedad de tipos de vestidos que debieron lucir las mujeres mayas de la antigüedad agrupados por tipos.

De entre todas estas prendas, las que se han consagrado a lo largo de la historia de esta civilización como las más significativas han sido los huipiles. ${ }^{50}$ Este es el tipo de vestido que luce la mujer representada en la pintura mural de Chilonché.

Los vestigios pictóricos en la pared Sur de dicho mural nos permiten distinguir parte del rostro de perfil, los codos, fragmentos de sus antebrazos, incluso parte de su mano izquierda y el cuerpo prácticamente completo de la dama, a excepción del pecho y de algunas pequeñas partes a la altura de las rodillas que se encuentran agrietadas. De esta forma, contemplamos la prenda de vestir casi en su totalidad. Vemos como cae desde la zona donde estarían ubicados los hombros hasta los tobillos dejando los brazos y los pies descalzos al descubierto. La pieza está adornada por una forma geométrica donde se distinguen los colores rojo, ocre e incluso levemente el azul, que cubre prácticamente toda la tela recortándose sobre un fondo de tonos grisáceos. Además, el borde inferior de la vestimenta presenta una suerte de flecos lisos y negros que cuelgan a modo de decoración. Desconocemos si nuestra protagonista portaba joyas en la muñeca derecha, en las manos, en la cabeza o en el cuello, o si el huipil contemplaba algún otro tipo de ornamentación en la parte superior.

En cuanto a la postura, se muestra erguida y altiva. Su cuerpo y sus pies ligeramente de perfil orientados hacia el flanco derecho de la escena, realzan sus curvas. La posición de los codos y la ligera apreciación de su mano izquierda nos indican que tenía los brazos levantados con las palmas orientada arriba. La cabeza vira hacia la izquierda, contraria al cuerpo, y parece ligeramente levantada con el cuello estirado. A su costado y rozando con su frente el brazo izquierdo de la dama encontramos la figura de una anciana encorvada que mira hacia el suelo y sujeta con el puño de su mano derecha un elemento difícil de determinar. Dicho objeto, aparentemente ligero y alargado conformado por una serie de pequeñas esferas en hilera, recuerda a primera vista a un bastón de apoyo.

El hecho de que Ix K'anpat Ajaw aparezca representada de esta forma tan solemne en la escena junto a una figura que parece inclinarse ante ella y luciendo un hermoso huipil bordado, es indicador de que el artista representaba a una mujer de la nobleza, pero ¿por qué decidió plasmar este atributo iconográfico en su vestido?

47 VIDAL LORENZO, Cristina; MUÑOZ COSME, Gaspar, 2015, 2016; MUÑOZ COSME, Gaspar; VIDAL LORENZO, Cristina; MERLO, Alessandro, 2014; VIDAL LORENZO, Cristina; MUÑOZ COSME, Gaspar; VÁZQUEZ DE ÁGREDOS PASCUAL, Ma Luisa, 2014; VÁZQUEZ DE ÁGREDOS PASCUAL, Ma Luisa; VIDAL LORENZO, Cristina; MUÑOZ COSME, Gaspar, 2014; y MUÑOZ COSME, Gaspar; VIDAL LORENZO, Cristina, 2019.

${ }^{48}$ MUÑOZ COSME, Gaspar; VIDAL LORENZO, Cristina, 2019, p. 92-93.

49 BARRIOS, Lina et. al., 2016.

${ }^{50}$ Veáse nota 21. 


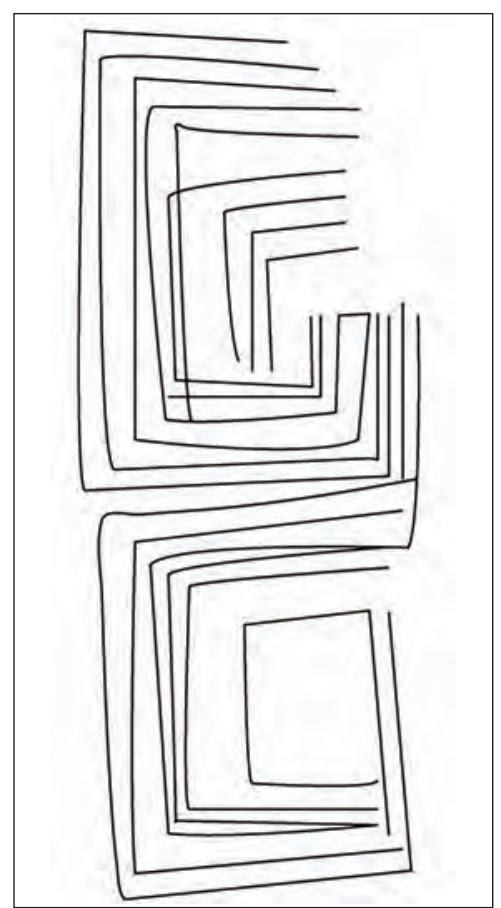

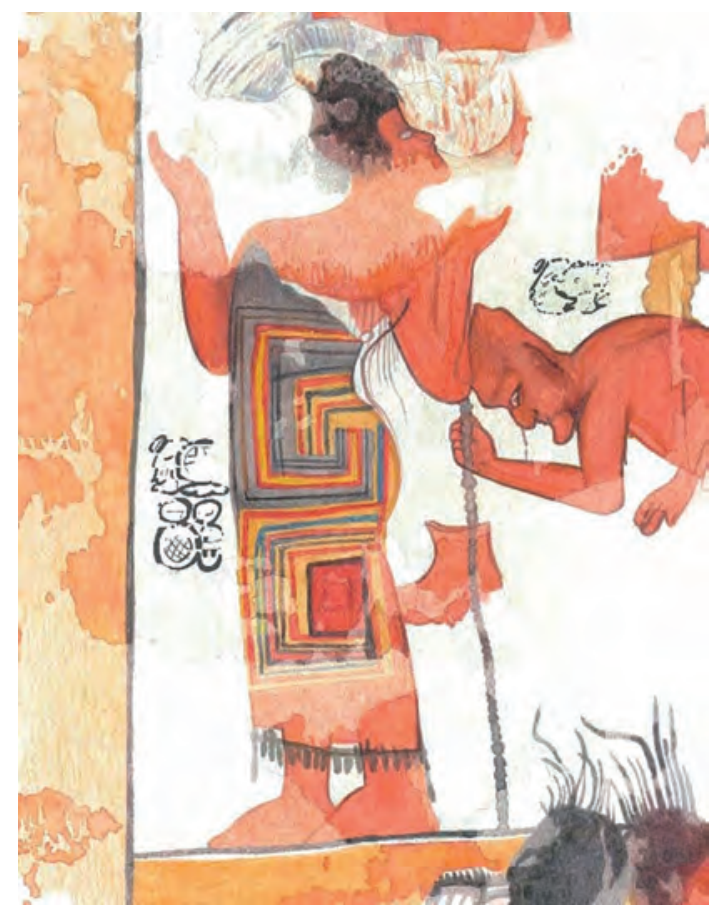

b

Fig. 5. a) El símbolo de grecas en espiral. Dibujo de la autora. b) Detalle de la pintura mural de la pared Sur, Cuarto 6, Edificio 3E1, Chilonché. Dibujo de Miguel Ángel Núnez / ㄷ Proyecto la Blanca 2014.

A continuación, tratamos de profundizar en el significado del símbolo proponiendo una serie de semejanzas con otros atributos iconográficos hallados en representaciones mayas que nos puedan permitir aproximarnos a la función comunicativa que cumplía este elemento en la escena.

Existen múltiples representaciones en el área maya en las que se observan, sobre los textiles, cenefas o elementos aislados construidos a partir de líneas geométricas. Se hallan numerosos ejemplos tanto en obras de arte prehispánicas, siendo uno de los más representativos el huipil que luce la Señora Xook en el dintel 24 de Yaxchilán, como en patrones textiles que se siguen bordando hasta la actualidad. En el catálogo "Diseño e iconografía de Chiapas" editado en 2006, se encuentran abundantes ejemplos contemporáneos. ${ }^{51}$ No obstante, en ninguna de las representaciones femeninas del arte maya revisadas hasta la fecha hemos encontrado un atributo iconográfico representado de la misma forma que el símbolo que ahora estudiamos. Por ello, recurrimos al análisis de otros sím- bolos similares o relacionados, hallados en diferentes expresiones artísticas y culturales mayas, aunque no aparezcan necesariamente plasmados sobre un huipil.

Las líneas coloreadas del huipil describen un recorrido serpentino que hemos denominado "grecas en espiral" y que, en primer lugar, nos recuerda al símbolo MUYAL descrito anteriormente (Fig. 3). Tal y como concluíamos en el apartado previo, dicho patrón está ligado a la fertilidad femenina, cualidad de las mujeres sumamente venerada por la cultura maya. Por ello, no debemos descartar que este significado esté relacionado con el del símbolo que luce la mujer pintada en Chilonché.

No obstante, somos conscientes de que las coincidencias no son exactas dado que el símbolo representado en el huipil de Ix K'anpat Ajaw no está conformado por líneas curvas, sino rectas, y es vertical. En esta posición la variante más parecida sería la que aparece dibujada en el brazo izquierdo de la Diosa Ix Chel en el mencionado vaso cilíndrico (Fig. 3b).

${ }^{51}$ VÁZQUEZ Y DE LOS SANTOS, Elena (coor.), 2006. 
Por otra parte, Dupiech, de manera independiente a la identificación del símbolo "S", hace referencia a otros símbolos también relacionados con el agua y la fertilidad, las grecas. ${ }^{52}$ Conservadas en otro de los textiles rescatados del cenote en Chichen Itzá y dibujada en la falda de la divinidad femenina en el fragmento $21 \mathrm{~b}$ del Códice de Madrid..$^{53}$ En este caso no dedica un espacio a profundizar en su significado puesto que se trata de un atributo que, aunque todavía perdura en Guatemala y en la región de Chiapas en México, no ha pervivido en la Península de Yucatán, objeto de su estudio. No obstante, para nosotros resulta relevante en tanto que sus líneas rectas recuerdan al diseño estudiado en el huipil de la dama representada en las pinturas de Chilonché. Además, tal y como se expone al principio del epígrafe, tanto el símbolo "S" como la representación de las grecas son asociadas con el agua y la fertilidad.

Dupiech exponía que las citadas grecas fueron unos símbolos presentes en los textiles de la península de Yucatán y que, según los vestigios artísticos y arqueológicos estudiados, todo apunta a una relación de este elemento con el agua, pero no lo encuentra en la iconografía textil de la actualidad. No obstante, existe un soporte que todavía conserva ricas muestras con esta forma geométrica hoy en día, nos referimos a la decoración arquitectónica de los edificios de estilo Puuc y más concretamente a aquellos que George F. Andrews engloba dentro de los subestilos "Mosaico" y "Uxmal Tardío". ${ }^{54}$ En los edificios de Kabah, Labná, Sayil, Xlapak y, especialmente, en Uxmal hallamos, entre los numerosos atributos iconográficos que ornamentan sus fachadas, grecas escalonadas, grecas en forma de doble $\mathrm{G}$, mascarones con orejeras de diseños geométricos, así como serpientes con cuerpos estilizados reducidos a líneas rectas junto a abundantes representaciones de mascarones con nariz larga, tradicionalmente identificados con Chaahk.

De entre los ejemplos hallados que guardan considerable similitud con el diseño bordado en el huipil plasmado en las pinturas murales de Chilonché (Figs. 5a y 5b), destacamos las grandes grecas que flanquean una de las bóvedas de la fachada este del Palacio del Gobernador en Uxmal (Fig. 6a) y las decoraciones geométricas en el paramento superior de la fachada del edificio poniente del cuadrángulo de las Monjas, también en Uxmal (Fig. $6 b)$. De hecho, Trevelyan y Forbes, apuntaron que el estilo arquitectónico desarrollado por las élites del Puuc pudo haber estado inspirado en los diseños simbólicos de los textiles del Clásico, con el fin último de crear un estilo propio, acorde con el nuevo orden político..$^{55}$

Dichas decoraciones arquitectónicas dotan a los edificios de una fuerte carga simbólica $y$, en este caso, el papel de las grecas podría aportarnos pistas para la interpretación de nuestro objeto de estudio.

El tipo de greca más estudiado dada su prolífica presencia en el arte mesoamericano ha sido la "greca escalonada". Una de las conclusiones que nos resulta más llamativa es aquella a la que llega Baudez:

"En caso de que la greca escalonada represente efectivamente el acceso al mundo subterráneo y de que los T sean signos de fertilidad, se puede proponer la hipótesis de que el conjunto expresa fertilidad proveniente de las entrañas de la tierra" ${ }^{56}$

En este estudio la greca no está directamente asociada con la fecundidad, pero sí forma parte de un conjunto en el que aparecen referencias a la misma, actuando como alegoría de la cueva. En este sentido, es sobradamente conocida la asociación de la cueva con el agua en la cosmovisión maya al tratarse de cavidades húmedas formadas en la roca por las cuales discurren ríos subterráneos, accesos al Inframundo según las antiguas creencias.

Por otra parte, la presencia de las grecas en la arquitectura del Puuc, en cualquiera de sus formas, suele ir unida a la presencia de mascarones tradicionalmente interpretados como deidades de la Iluvia, lo que podría considerarse también como un punto de partida para entender una relación entre estas con el agua.

En última instancia, no podemos dejar de mencionar la posible relación entre este símbolo y la ser-

\footnotetext{
52 DUPIECH CAVALERI, Danielle, 2017, p. 145.

${ }_{53}$ Para consultar la versión digital del Códice de Madrid véase: FAMSI. "El Códice Madrid" (en línea) En: http://www.famsi. org/spanish/mayawriting/codices/madrid.html (Fecha de consulta: 6-7-2018).

${ }^{54}$ ANDREWS, George F., 1986.

55 TREVELYAN, Amelia M.; FORBES, Heather W., 2002.

${ }^{56}$ BAUDEZ, Claude F., 2004, p. 95.
} 


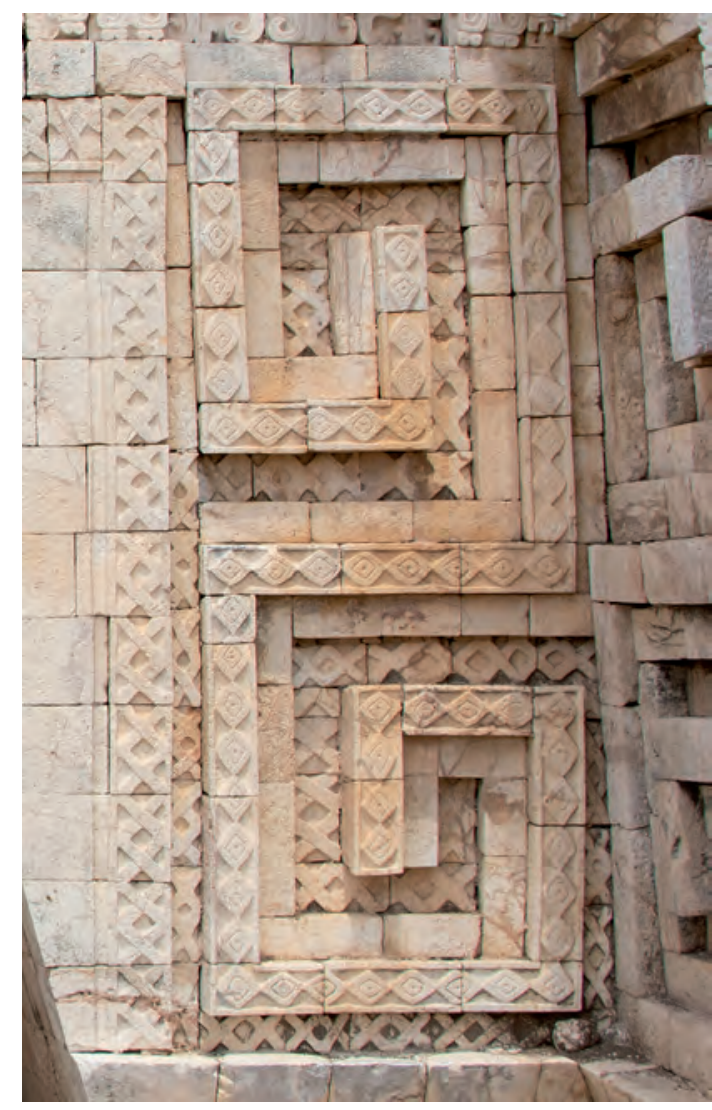

a

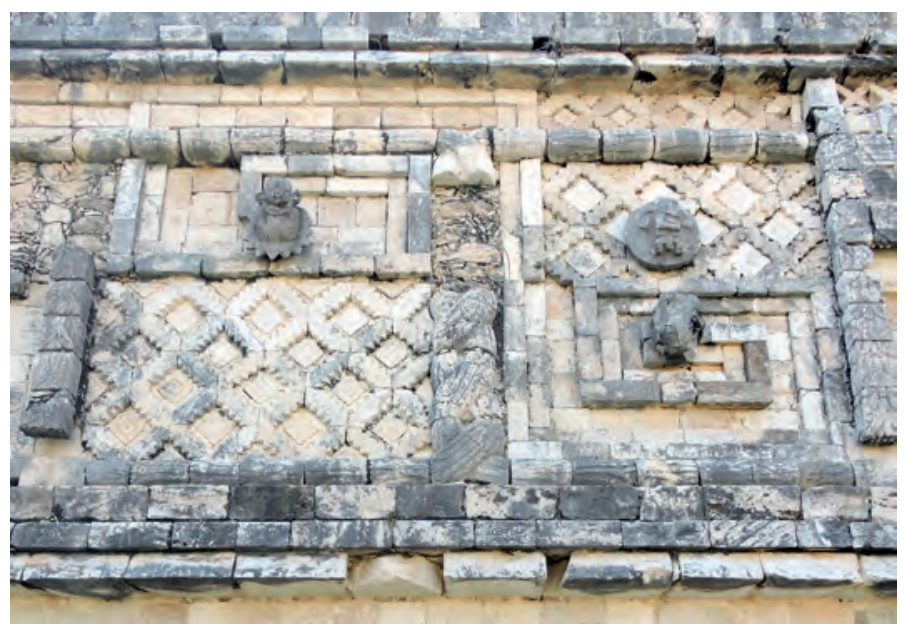

b

Fig. 6. a) Detalle de la fachada Este del Palacio del Gobernador de Uxmal. Fotografía de Riccardo Montuori. b) Detalle de la fachada del Edificio poniente del Cuadrángulo de las Monjas de Uxmal. Fotografía de Ana Rosado.

talle con formas rectas en la arquitectura y no sinuosas como sería más natural.

piente. Las grecas labradas en la fachada del edificio poniente del Cuadrángulo de las Monjas de Uxmal (Fig. 6b) culminan su espiral con sendos salientes que representan cabezas de ofidios. De este modo, las líneas rectas de la greca conformarían el cuerpo de dos serpientes o una única serpiente bicéfala. Por otro lado, si prestamos atención al diseño que enmarcan las líneas que constituyen las grandes grecas en espiral en la fachada del Palacio del Gobernador (Fig. 6a), encontramos ciertos paralelismos con los dibujos que se advierten en la piel de algunas serpientes propias de Mesoamérica como la crotalus durisos comúnmente conocida como serpiente de cascabel. De hecho, existen numerosas investigaciones, que apuntan la presencia de esta víbora y de muchas otras en algunas representaciones artísticas mayas. ${ }^{57} \mathrm{Y}$ "los procesos de simplificación -de extremada geometrización" a los que se refiere Gendrop, ${ }^{58}$ podrían explicar que el cuerpo de las serpientes se

Estos animales son prolíficos en la iconografía maya pues están fuertemente ligados a sus creencias y se muestran en el arte, representados de múltiples formas, en diferentes soportes y asociados a multitud de significados. Y, precisamente, la Diosa Chac Chel es una de las principales divinidades asociada con la serpiente. Esto se debe a que, al tratarse de un animal de tierra, como el jaguar, también está relacionado con la fertilidad de la misma. Suele aparecer en los códices tocada con una serpiente en la cabeza cuyo cuerpo, como ya hemos visto también anteriormente, a veces tiene la forma de una S. Uno de los paradigmas entre estas representaciones en el que se puede observar claramente la serpiente en su tocado es el dibujo de la anciana diosa en la última página del Códice de Dresde protagonizando un diluvio. ${ }^{59}$

\footnotetext{
57 Véase DE LA GARZA, Mercedes, 1984 o SANDOVAL, Priscila, 2009, entre otras.

58 GENDROP, Paul, 1983, p. 190

59 Para consultar una versión digital del Códice de Dresde véase: FAMSI. "El Códice Dresde" (en línea) En: http://www.famsi. org/spanish/mayawriting/codices/dresden.html (Fecha de consulta: 6-7-2018).
} 
Tras este recorrido observamos que todos aquellos símbolos en los que hemos hallado una similitud con las formas estudiadas en el atributo pintado sobre el huipil de la dama de Chilonché están de un modo u otro relacionados con una de las características naturales inherentes a las mujeres en todos los lugares y en todos los momentos de la historia, que es la de ser fértiles, procuradoras de vida. Cualidad que, iconográficamente, contribuye a la construcción del género femenino en el arte maya a lo largo de su historia con continuas referencias, ya sea a través de atributos iconográficos como las flores o el maíz, de animales como el jaguar, el conejo o la serpiente, o de la plasmación del acto mismo de dar a luz o de cuidar a los infantes, entre otros. Incluso la acción misma de tejer está considerada como una metáfora de la creación de la vida. Remito nuevamente al trabajo de Vidal, Vázquez de Ágredos y Horcajada en el que se cuenta cómo en algunas comunidades mayas actuales todavía se entiende el acto de enrollar el hilo en torno al uso como una metáfora del feto creciendo en el vientre de la madre. ${ }^{60}$ Como se ha podido comprobar, según los expertos, tanto las grecas, como las serpientes y las nubes en la cosmovisión maya estuvieron relacionadas en numerosas ocasiones con el agua y la fertilidad de la tierra.

De este modo, podríamos concluir que, al vestir un huipil de estas características, esta noble representa su condición de mujer fértil heredada de la Diosa de la Luna. Cualidad que, como observamos en otras representaciones, era sumamente valorada en la civilización maya al darles a ellas la potestad de determinar la línea de sangre y legitimar el poder del gobernante en su ascenso al trono.

Por otro lado, no podemos eludir la cuestión de que, pese al parecido encontrado entre el símbolo de Chilonché y los diseños de grecas en espiral propios del estilo Uxmal Tardío en la región del Puuc, la distancia geográfica entre ambos territorios es considerable.

Por ello, cabe señalar que todos los conceptos estudiados, independientemente de su forma de representación, el soporte en el que se han encontrado, o de su adscripción a una cultura y a un territorio geográfico, concretos, son transversales en las creencias mesoamericanas, forman parte de lo que López Austin acuñó como "el núcleo duro" en la tradición mesoamericana que mencionábamos al inicio de este trabajo. ${ }^{61} Y$, en consecuencia, se encuentran representados de múltiples formas a lo largo y ancho de todo el territorio formando parte de una misma tradición de pensamiento, de una misma cosmovisión.

\section{Conclusión}

Si bien es cierto que por sí solos, los elementos estudiados no determinan el significado de las imágenes, sí actúan como piezas de ese gran puzle que es la obra de arte. Por ello consideramos tan relevante su análisis.

Dado que cada uno de los símbolos se manifiesta en representaciones diferentes y no aparecen combinados en una misma imagen, se han analizado de manera independiente tratando de arribar a unas conclusiones específicas para cada uno. No obstante, en los tres casos hemos llegado a deducciones similares acerca de la consideración de la mujer en la cultura maya. Obviamente, el estudio de la construcción del género en el arte maya requiere una investigación mucho mayor, pero estos elocuentes símbolos comienzan a aportarnos nuevas evidencias sobre esta cuestión en particular, y sobre el pensamiento maya en general.

La tentativa vinculación entre el símbolo de las tres circunferencias y las piedras del horno, relaciona este símbolo con la cocina, con el alimento y con la creación. Por su parte, el símbolo de la S horizontal refiere a las nubes y por tanto a la lluvia y a la fertilidad. Y, por último, el símbolo de las grecas en espiral, puede asociarse, como se ha visto, con el propio MUYAL o símbolo de la S horizontal, así como con la serpiente. Lo que significa que, por ende, seguramente estaba ligado también con la tierra y la fertilidad. En síntesis, todos tienen en común la referencia a la capacidad intrínseca de la mujer como procuradora de vida. La mayoría de los estudios sobre mujeres y de género en el área maya, ${ }^{62}$ Ilegan precisamente a la conclusión de que, independientemente de cómo fuera la división de géneros en el área maya, si es que la hubo en el sentido que nosotros conocemos, lo que sí es seguro es que la fertilidad de la mujer constituye uno de los pilares fundamentales de su cosmovisión, al estar directamente vinculada, tan-

60 VIDAL LORENZO, Cristina; VÁZQUEZ DE ÁGREDOS, Mª Luisa; HORCAJADA CAMPOS, Patricia, 2011, p. 89.

61 LÓPEZ AUSTIN, Alfredo, 2001, p. 47-65.

62 Véase, por ejemplo: STONE, 1991, p. 200-202; JOYCE, Rosemary A., 1993; HEWITT, Erika, 1999, p. 260; CRUZ CORTÉS, Noemí, 2005, p. 31-44; RODRÍGUEZ-SHADOW, María J., 2016, p. 63; o VIDAL LORENZO, Cristina; RIVERA DORADO, Miguel, 2017, p. 62-71. 
to con el origen de la creación como con la continuidad de la vida y, en ámbitos políticos, con la legitimidad del poder regio. Y, por ello, existen numerosas formas simbólicas, especialmente en la indumentaria de las señoras, que aluden continuamente a ello. Lo que significa que, finalmente, estos diseños plasmados sobre los textiles no eran arbitrarios, sino que formaban parte de la red de significados que los artistas mayas, comisionados por la nobleza, trazaban en el arte con una clara intención comunicativa.

\section{Bibliografía}

AMILBURU, María G. "La cultura como universo simbólico en la antropología de E. Cassirer". Pensamiento, 1998, vol. 209, no 98, p. 221-244.

ANDREWS, George F. Los estilos arquitectónicos del Puuc. Una nueva apreciación. Ciudad de México: Instituto Nacional de Antropología e Historia, 1986.

ASTURIAS DE BARRIOS, Linda. Comalapa: el traje y su significado. Ciudad de Guatemala: Museo Ixchel del Traje Indígena de Guatemala, 1985.

BARRIOS, Lina et al. Indumentaria Maya Milenaria. Ciudad de Guatemala: Ministerio de Cultura y Deportes, 2016.

BAUDEZ, Claude François. Una historia de la religión de los antiguos Mayas. México: UNAM, CEMCA Y CCCAC, 2004

BRUHNS, Karen Olsen. "Yesterday the queen wore... an analysis of women and costume in the public art of the late classic maya". En: MILLER, V. (ed.), The Role of Gender in Precolumbian art and Architecture. Boston: University Press of America, 1988, p. 105-134.

CASSIRER, Ernst. Filosofía de las formas simbólicas. 2 vols. México: Fondo de Cultura Económica, 1971.

CHEVALIER, Jean. Diccionario de los símbolos. Barcelona: Editorial Herder, 1986.

DE LA GARZA, Mercedes. El Universo Sagrado de la Serpiente entre los Mayas. Ciudad de México: Universidad Nacional Autónoma de México, 1984.

CRUZ CORTÉS, Noemí. Las Señoras de la Luna. México: Universidad Nacional Autónoma de México, 2005.

DOUGLAS, Mary. Símbolos naturales. Exploraciones en cosmología. Madrid: Alianza Editorial, 1988.

DUPIECH CAVALERI, Danielle. Textiles Mayas. La trame d'un peuple. Paris: Éditions UNESCO, 1999.

DUPIECH CAVALERI, Danielle. Tradition Textile Maya du Yucatán (Mexique XXIe siècle) Usage rituels et codes symboliques. Paris: L'Harmattan, 2017.

FAMSI. "El Códice Dresde" (en línea) En: http://www. famsi.org/spanish/mayawriting/codices/dresden.html (Fecha de consulta: 6-7-2018).

FAMSI. "El Códice Madrid" (en línea) En: http://www. famsi.org/spanish/mayawriting/codices/madrid.html (Fecha de consulta: 6-7-2018).

FREIDEL, David; SCHELE, Linda; PARKER, Joy, Maya Cosmos. Three Thousand Years on the Shaman's Path. Nueva York: Quill William Morrow, 1993.

FRUTIGER, Adrián. Signos, símbolos, marcas, señales. Elementos, morfología, representación, significación. Barcelona: Editorial Gustavo Gili, SL, 2007.

GARCÍA BARRIOS, Ana. Chaahk, el Dios de la Lluvia, en el Periodo Clásico Maya: Aspectos Religiosos y Políticos. Tesis doctoral. Madrid: Universidad Complutense de Madrid, 2008.
GARCÍA BARRIOS, Ana; VÁZQUEZ LÓPEZ, Verónica. "The Weaving of Power: Women's Clothing and Protocol in the Seventh-Century Kingdom of Kaanu'l". Latin American Indian Literatures Journal, 2011, vol. 1, n 27, p. 50-95.

GARCÍA MAHÍQUES, Rafael. Iconografía e Iconología. Volumen 2. Cuestiones de método. Madrid: Ediciones Encuentro, 2009.

GENDROP, Paul. Los estilos Río Bec, Chenes y Puuc en la arquitectura maya. México D.F.: Universidad Nacional Autónoma de México, 1983.

HENDRICKSON, Carol. Weaving Identities: Construction of Dress and Self in a Highland Guatemala Town. Austin: University of Texas Press, 1995.

HEWITT, Erika A. "What's in a name: Gender, power, and classic Maya women rulers". Ancient Mesoamerica, 1999, vol. 10, p. 251-262.

HOLSBEKE, Mireille; MONTOYA, Julia. Kemtzij, kemon taq tzij na' oj, Palabras y pensamientos Tejidos. Los tejidos mayas, espejos de una cosmovisión. Ciudad de Guatemala: Editorial Cholsamaj, 2008.

JOYCE, Rosemary. "Dimensiones simbólicas del traje en monumentos clásicos mayas: la construcción del género a través del vestido". En: ASTURIAS DE BARRIOS, L. FERNÁNDEZ GARCÍA, D. (eds.). La indumentaria y el tejido mayas a través del tiempo. Guatemala: Ediciones del Museo Ixchel, 1992, p. 29-38.

JOYCE, Rosemary. "Women's Work. Images of Production and Reproduction in Pre-Hispanic Southern Central America". Current Anthropology, 1993, vol. 34, $n^{\circ} 3$, p. 255-274.

JOYCE, Rosemary A. "Performing Gender in Pre-Hispanic Central America: Ornamentation, Representation, and the Construction of the Body," Anthropological Aesthetics, 1998, n 33, p. 147-165.

JUNG, Carl G. Arquetipos e Inconsciente colectivo. Barcelona: Paidós, 1970.

KETTUNEN, Harri; HELMKE, Christophe. Introducción a los Jeroglíficos Mayas. XVI Conferencia Maya Europea. Copenhague: Departamento de Lenguas y Culturas Indígenas, Instituto para Estudios Transculturales y Regionales, Universidad de Copenhague, 2011.

KOPALKOVA, Alla. Diseños mágicos. Análisis de los diseños con rombos en los huipiles mayas de Chiapas. Chiapas: Consejo Estatal para las Culturas y las Artes de Chiapas, 2018.

LE FORT, Geneviève. "Costume et royauté sacrée chez les mayas de la période classique: le costume 'en treiIlis '". Civilisations, 2002, n 50, p. 115-127.

LOOPER, Mathew G. Gifts of the Moon. Huipil Designs of the Ancient Maya. San Diego, California: San Diego Museum of Man, 2000.

LÓPEZ AUSTIN, Alfredo. "El núcleo duro, la cosmovisión y la tradición mesoamericana". En: BÁEZ-JORGE, F. y BRODA J. (coor.). Cosmovisión, ritual e identidad de los pueblos indígenas de México. México D.F.: Fondo de Cultura Económica, 2001, p. 47-65.

MACLEOD, Morna. "El traje como texto y la disputa de los signos". Revista Estudios Interétnicos, 2004, n 18, p. 31- 43.

MARTIN, Simon. "The Baby Jaguar: An exploration of Its Identity and Origin in Maya Art and Writing". En: TIESLER BLOS, V.; COBOS, R.; GREENE ROBERTSON, M. (coor.). La Organización Social entre los Mayas: Memoria de la Tercera Mesa Redonda de Palenque. 2 vols. Ciudad de México: Instituto Nacional de Antropología e Historia, 2002, vol. 1, p. 49-78. 
MILLER, Mary. "Extreme Makeover. How painted bodies, flattened foreheads, and filed teeth made the Maya beautiful". Archaeology, 2009, vol. 62, n 1, p. 36-42.

MORLEY, Sylvanus G. The Ancient Maya. California: Standford University, 1946.

MORRIS, Walter. Mil años del tejido en Chiapas. México D.F.: Instituto de Artesanía Chiapaneca, 1984.

MORRIS, Walter. Diseño e Iconografía Chiapas. Geometrías de la imaginación. Ciudad de México: Arte Popular de México, 2006.

MUÑOZ COSME, Gaspar; VIDAL LORENZO, Cristina. "El mural de Chilonché: estudio preliminar". Revista Española de Antropología Americana, 2019, nºspecial 49, p. 77-96.

MUÑOZ COSME, Gaspar; VIDAL LORENZO, Cristina; MERLO, Alessandro. "La Acrópolis de Chilonché (Guatemala): Crónica de las investigaciones de un patrimonio en riesgo en el área maya". Restauro Archeologico, 2014, n² 2, p. 99-116.

OTZOY, Irma. "Identidad y Trajes mayas". Mesoamérica, $1992, n^{\circ} 23$, p. 95-112.

PANOFSKY, Erwin. Estudios sobre iconología. Madrid: Alianza Editorial, 1979.

PARPAL CABANES, Esther. "Conociendo a los mayas a través de la Historia del Arte. El método iconográfico-iconológico". En: JUANES CORTÉS, A. et. al. (eds.). Teoría, Metodología y Casos de Estudio. Colección Temas y perspectivas de la Historia, número 6. Salamanca: Hergar Ediciones Antema, 2017, p. 747-759.

QUIROZ CARRANZA, Joaquín; CANTÚ GUTIERREZ, CitlaIli. "El fogón abierto de tres piedras en la península de Yucatán: Tradición y transferencia tecnológica". Revista Pueblos y Fronteras Digital, 2012, vol. 7, n 13, p. 270-301.

REENTS-BUDET, Dorie. Painting the Maya Universe: Royal Ceramics of the Classic Period. Londres: Duke University Press, 1994.

REILLY, F. Kent. "The Lazy-S: A formative Period Iconographic Loan to Maya Hieroglyphic Writing". En: MACRI, M.; MCHARGUE, J. (eds.). Eight Palenque Round Table, 1993. San Francisco: Pre-Columbian Art Research Institute, 1996, vol. X, p. 413-424.

RODRÍGUEZ-SHADOW, María J. Las mujeres mayas de antaño. México: Fundación Armella, 2016.

SANDOVAL, Priscila. Serpientes de Guatemala. Zoología e Iconografía. Ciudad de Guatemala: FLAAR, 2009.

STONE, Andrea. "Aspects of Impersonation in Classic Maya Art". En: GREENE ROBERTSON, M. (ed.). Sixth Palenque Round Table, 1986. Norman: University of Oklahoma Press, 1991, p. 194-202.

STONE, Andrea; ZENDER, Marc. Reading Maya Art. A Hieroglyphic Guide to Ancient Maya Painting and Sculpture. Londres: Thames \& Hudson Ltd, 2011.

THOMPSON, J. Eric S. A Catalog of Maya Hiroglyphs. Oklahoma: University of Oklahoma Press, 1962.
TREMAIN, Cara G. A Study and Identity in the Late Classic Maya Court. Tesis Doctoral. Calgary: Universidad de Calgary, 2017.

TREVELYAN, Amelia M.; FORBES, Heather W. "The Gendered Architecture of Uxmal". En: GUSTAFSON, L.S.; TREVELYAN, A. M. (eds.). Ancient Maya Gender Identity and Relations. Westport, Connecticut y Londres: Bergin \& Garbey, 2002, p. 93-140.

VÁZQUEZ DE ÁGREDOS PASCUAL, Ma Luisa; VIDAL LORENZO, Cristina; MUÑOZ COSME, Gaspar. "The role of new technology in the study of Maya mural painting: over a century of progress". En: VIDAL, C.; MUÑOZ, G. (eds.). Artistic Expressions in Maya Architecture: Analysisis and Documentacion Techniques. Oxford: BAR International Series 2693, Archaeopress, 2014, p. 165-178.

VÁZQUEZ Y DE LOS SANTOS, Elena (coor.). Diseño e Iconografía Chiapas. Geometrías de la imaginación. México: Arte Popular de México, 2006.

VIDAL LORENZO, Cristina; MUÑOZ COSME, Gaspar. "La Sala de las Pinturas de Chilonché y la Subestructura de la Acrópolis de La Blanca (6J2-Sub.2): resultados de las investigaciones arqueológicas pertenecientes a las temporadas de campo 2011-2013". Informes y Trabajos 2015. Excavaciones en el Exterior 2013, 2015, n 12, p. 207-218.

VIDAL LORENZO, Cristina; MUÑOZ COSME, Gaspar. "Chilonché y La Blanca. Arquitectura monumental en la cuenca del río Mopán". Arqueología mexicana, 2016, no 137, p. 60-67.

VIDAL LORENZO, Cristina; MUÑOZ COSME, Gaspar; VÁZQUEZ DE ÁGREDOS PASCUAL, Ma Luisa. "Reflexión en torno al arte y la conservación del patrimonio cultural maya". En: BENITO, D. (ed.). La piel de los edificios. Técnicas artísticas y formas de intervención sobre el patrimonio cultural: la Historia del Arte como reflexión y compromiso. Valencia: Universitat de València, 2014, p. 141-158.

VIDAL LORENZO, Cristina; PARPAL CABANES, Esther. "Símbolos de poder entre las mujeres mayas de la élite. Un análisis iconográfico de los ornamentos femeninos". Boletín de Arte, 2016, $\mathrm{n}^{\circ}$ 37, p. 227-241.

VIDAL LORENZO, Cristina; PARPAL CABANES, Esther. "Ámbitos femeninos en la arquitectura maya". En: VASILEVA IVANOVA, A. (ed.). Espacio, género, memoria: Discurso académico y práctica socioespacial. Valencia: Tirant Humanidades, 2017, p. 45-52.

VIDAL LORENZO, Cristina; RIVERA DORADO, Miguel (eds.). Popol Vuh. Madrid: Alianza Editorial, 2017.

VIDAL LORENZO, Cristina; VÁZQUEZ DE ÁGREDOS, $M^{a}$ Luisa; HORCAJADA CAMPOS, Patricia. "La indumentaria de los personajes femeninos de la élite maya y el papel de la mujer en su elaboración". En: SOLANILLA, V. (ed.). Actas de las V Jornadas Internacionales de Textiles Precolombinos. Barcelona: Universitat Autònoma de Barcelona, 2011, p. 81-92. 